\section{Forces and Structures of the Herpes Simplex Virus (HSV) Entry Mechanism}

Richard W. Clarke*

University of Cambridge Chemistry Dept, Lensfield Rd, Cambridge, UK

Abstract: This paper discusses physical and structural aspects of the mechanisms HSV uses for membrane fusion. Calculations show that Herpes simplex virus glycoprotein D has such avidity for its receptors that it can hold the virion against the plasma membrane of a neuron strongly enough for glycoprotein $B$ to disrupt both leaflets of the bilayer. The strong electric field generated by the cell potential across perforations at this disruption would break the hydrogen bonds securing the gB fusion loops, leading to fusion of the plasma and viral membranes. This mechanism agrees with the high stability of the tall trimeric spike structure of $\mathrm{gB}$ and is consistent with the probable existence of a more compact initial conformation that would allow it to closely approach the plasma membrane. The release of the fusion domains by disruption of hydrogen bonds is shared with the endocytotic entry pathway where, for some cell types not punctured by $\mathrm{gB}$, the virus is able to induce inward forces that cause endocytosis and the fusion loops are released by acidification. The puncture:fusion mechanism requires low critical strain or high tissue strain, matching primary tropism of neural processes at the vermillion border. In support of this mechanism, this paper proposes a functional superstructure of the antigens essential to entry and reviews its consistency with the experimental evidence.

Keywords: Herpes simplex virus; critical stress; membrane fusion; entry mechanism.

\section{Introduction}

Herpes simplex virus 1 and 2 (HSV) virions infect cells via specific interactions between viral glycoproteins and cellsurface receptors that lead to the virion envelope fusing with either an endosome or the plasma membrane, to create a fusion pore through which the tegument proteins and genome-containing capsid are released into the cytoplasm. There are three glycoprotein antigens essential to entry, gB, $\mathrm{gD}$ and $\mathrm{gHgL}$, a heterodimer. ${ }^{1-6}$ These are illustrated in Fig. 1. The viral fusogen is $\mathrm{gB}$, whose stable ectodomain structure is a $16 \mathrm{~nm}$ long trimeric spike ${ }^{7,8}$ with three movable arms incorporating lipophilic domains ${ }^{8}$ called fusion loops, that are held away from the solvent by hydrogen bonds but associate with lipid membranes once released. ${ }^{9}$ Viral fusogens usually produce membrane fusion by coupling it to a large free energy change during conformational rearrangements from an initial metastable structure $^{10-12}$ but although a compact form of $\mathrm{gB}$ has been computationally reconstructed, ${ }^{13}$ it is known to be much less stable than the spike configuration ${ }^{14}$ and has proven impossible to crystallize. ${ }^{15}$ Nevertheless, for the physical and structural reasons in Sections 1 and 3 respectively, this paper generally assumes that the compact form of $\mathrm{gB}$ does exist. Two of the other essential HSV glycoproteins form an interwoven heterodimer, $\mathrm{gHgL}^{16}$ that has a putative binding domain for $\mathrm{gB}^{17}$ halfway along its $11 \mathrm{~nm}$ ectodomain. This paper shows how $\mathrm{gHgL}$ could sterically stabilize the compact form of $\mathrm{gB}$, only binding to it once destabilized.
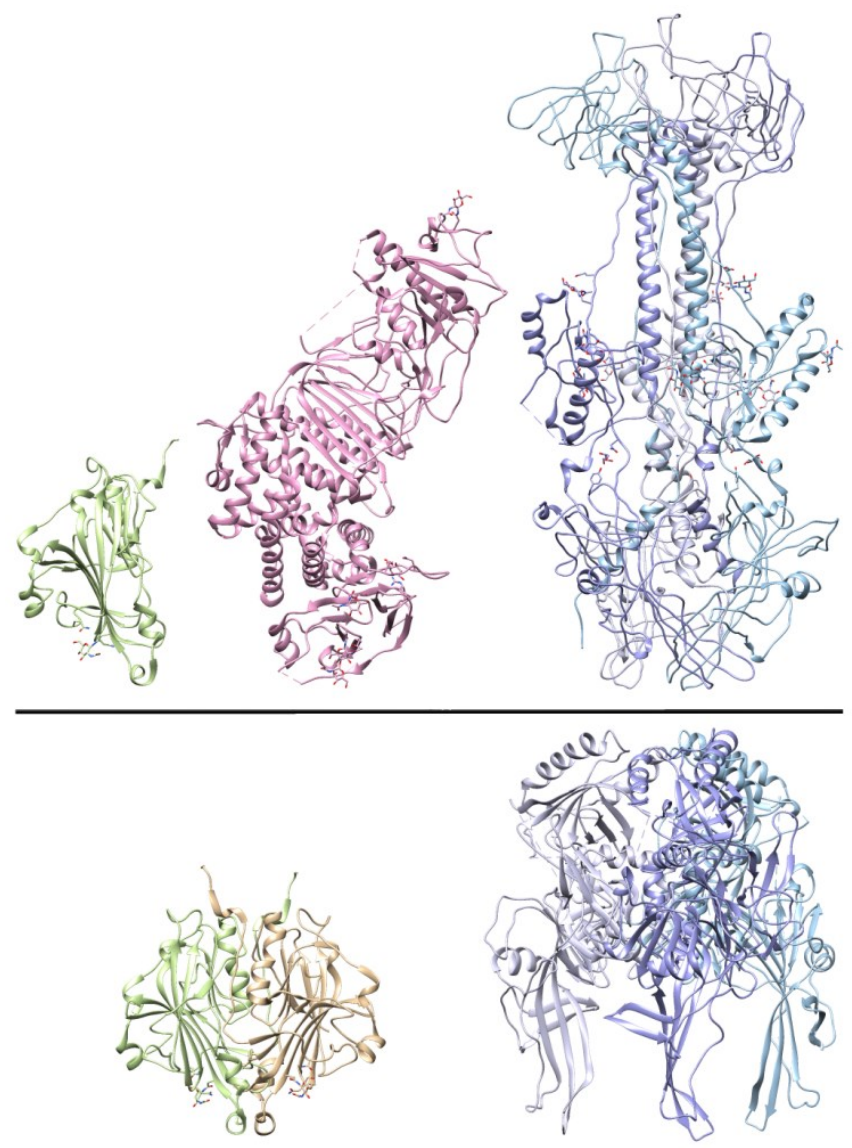

Figure 1. Structured ectodomains of the essential HSV glycoproteins. $\mathrm{gD}$ (green) binds at least three entry receptors despite its small size. $\mathrm{gHgL}$ (pink) is a heterodimer. gB (grey, blue \& cyan) is the fusogen. Below the $20 \mathrm{~nm}$ scale bar, upon which the antigens are vertically centred, are shown dimeric $\mathrm{gD}$ and the compact form of $\mathrm{gB}$.

The fourth essential glycoprotein, $\mathrm{gD}$, has an ectodomain approximately $6 \mathrm{~nm}$ in size, ${ }^{18}$ and binds at least three cellsurface receptors. The binding domains for these receptors are initially obstructed by a largely disordered loop, with a profusion domain (PFD) essential to entry, ${ }^{19-22}$ that leads to the $\mathrm{gD}$ transmembrane domain. This chain is displaced by either of the main $\mathrm{gD}$ receptors, Nectin (Nectin-1 or Nectin2) or HVEM (Herpes Virus Entry Mediator), ${ }^{23,}{ }^{24}$ or by binding 3-O-sulfated heparan sulfate (3OSHS), ${ }^{25-27}$ after which it induces a structural transition in $\mathrm{gHgL}$ that enhances its affinity for $\mathrm{gB}^{28}$ and then remains bound to $\mathrm{gHgL}$ and $\mathrm{gB}$ in a supercomplex. ${ }^{28-30}$ The gD loop is at least 37 residues long, ${ }^{31}$ approximately $13.32 \mathrm{~nm}^{32}$ This estimation only accounts for residues 270-306 of the ectodomain though; the transmembrane region does not actually begin for another 35 residues, at position $341 .^{33}$

Although gD is essential for entry, an HSV virion with the other glycoproteins present as normal can still enter a cell 
with all but one or two out of approximately $335 \mathrm{gD}$ glycoproteins missing ${ }^{34}$ or capped by antibody. ${ }^{35}$ This paper calculates that the avidity of the cellular receptors for HSV $\mathrm{gD}^{36,37}$ would hold $\mathrm{gB}$ strongly enough against the plasma membrane of a neuron to allow $\mathrm{gB}$ to produce membrane fusion by transiently puncturing it. The membrane potential of a live cell across such a puncture would make an electric field strong enough to disrupt hydrogen bonds. In common with the low $\mathrm{pH}$ on the endocytotic entry pathway to epithelial cells, this disruption of hydrogen bonds would release the $\mathrm{gB}$ fusion loops.

On tough cells with high critical strains or stresses an initial failure of $\mathrm{gB}$ to puncture the membrane does not necessarily stop infection because on some non-neuronal cell types the virus is able to induce cellular forces that produce endocytosis, by the interaction of $\mathrm{gHgL}$ with $\alpha \mathrm{v} \beta 6$ or $\alpha \mathrm{v} \beta 8$ integrins. ${ }^{38}$ On this entry pathway endosome acidification releases the $\mathrm{gB}$ fusion loops instead. In this way the hypothesis agrees with the respective entry pathways found for neurons and epithelial cells, with entry at the plasma membrane for neurons, and endocytotic entry for tougher cells like keratinocytes. ${ }^{39}$ However, there is a common mechanism for the secondary activation of $\mathrm{gB}$; the release of its fusion domains by the disruption of hydrogen bonds.

In this paper I quantitatively review the interactions of the $\mathrm{gD}, \mathrm{gHgL}$ and $\mathrm{gB}$ ectodomains and discuss how they induce the fusion of the viral membrane with the plasma membrane or an endosomal membrane, allowing capsid entry.

\section{Physics of HSV entry}

\subsection{Targeted membrane rupture}

In order for areal strain to rupture a membrane its thermal undulations must first be smoothed out by a low stress before the critical stress required for rupture is applied. ${ }^{40}$ This pre-tensioning is achieved by the binding sequence of the HSV glycoproteins: Firstly, gB and the non-essential glycoprotein $\mathrm{gC}$ adhere to the cell surface via heparan sulfate. $^{41}$ The multiplicity of these low affinity interaction sites generates a high overall avidity while allowing the virion to roll around on the cell surface, ${ }^{42}$ exploiting cell movement and bulk tissue strain to gradually bind more tightly. In this way $\mathrm{gHgL}$ can bind an $\alpha \mathrm{V} \beta 3$ integrin, ${ }^{43}$ routing the virus to cholesterol-rich rafts, ${ }^{44}$ and HSV-1 gB may consolidate or constrain this localization by binding to a receptor called PILR $\alpha .^{45-47}$ Once the virion envelope is close enough to the plasma membrane, $\mathrm{gD}$ is able to bind HVEM, Nectin or 3-O-sulfated heparan sulfate, releasing its profusion domain which binds $\mathrm{gHgL}$ and $\mathrm{gB}^{24}$ The association of the $\mathrm{gD}$ profusion domain with $\mathrm{gB}$ and $\mathrm{gHgL}$ is known to greatly increase the probability of membrane fusion and virion entry. ${ }^{29,}{ }^{30} \mathrm{We}$ see later that the free $\mathrm{gD}$ profusion domain likely causes $\mathrm{gHgL}$ to release $\mathrm{gB}$ from an initial compact conformation. In this way it maximizes the local strain of the plasma membrane because the presence of the $\mathrm{gD}$ chain guarantees that the plasma membrane is already adjacent and under tension.

The binding energy of each $\mathrm{gD}$ receptor would do a small amount of work pre-tensioning the virus against the plasma membrane. Membrane tension would be ratcheted up by each binding event because of the remarkably small size of $\mathrm{gD}$ relative to $\mathrm{gB}$, even in its proposed compact form, ${ }^{13}$ and because forces on $\mathrm{gD}$ would be transmitted to $\mathrm{gB}$ both via their common anchor point in the virion envelope ${ }^{48}$ and via the hinged ${ }^{49}, 50$ c-terminal chain, or loop, of $\mathrm{gD}$, once attached to $\mathrm{gB} .^{28-30} \mathrm{gD}$ has recently been shown to trans bind to the side of Nectin- $1,{ }^{31,51}$ to its cis dimerization site ${ }^{52}$ this allows Nectin to bind gD while lying flat in between the two membranes, pulling them to within $6-8 \mathrm{~nm}$ of each other. ${ }^{15}$ The ectodomain of HVEM is a similar size to nectin- $1,{ }^{15,26}$ so binding these receptors pulls the virion envelope about as close to the plasma membrane as is realistically possible.

Apart from the main $\mathrm{gD}$ receptors, Nectin-1 and HVEM, HSV-1 gD has another binding site, for 3-O-sulfated heparan sulfate (3OSHS) ${ }^{27}$. When covalently linked to the short but specific saccharide sequence of 3-O-sulfated heparan sulfate that binds HSV-1 gD, ${ }^{27,53,54}$ the Syndecan 1 \& 2 proteoglycans are full entry receptors for $\mathrm{HSV}-1 .^{25}$ Syndecans have a strong functional homology with Nectin: They are also involved in cell adhesion, ${ }^{55}$ do not protrude far from the plasma membrane, because of protease cleavage sites in their extracellular domains, ${ }^{53}$ and can also transduce signals to the cell interior via phosphorylation sites on their cytoplasmic domains. ${ }^{56}$ Furthermore, the binding site for 3 OSHS on HSV-1 gD is next to the HVEM binding site, ${ }^{26}$ consistent with 3OSHS displacing the gD linker in the same way as HVEM or Nectin. ${ }^{25}$ All of the above characteristics match the requirements for 3OSHS-Syndecan to function in the proposed entry mechanism in exactly the same way as HVEM or Nectin: The short 3OSHS motif, covalently bonded to a securely anchored Syndecan, displaces the gD linker upon binding and has enough affinity to support plasma membrane disruption by $\mathrm{gB}$.

Any two of these binding sites, let alone three or four on two or more gD antigens, ${ }^{15}$ would generate an exceptionally high avidity. A lower estimate for the strength of the interaction is the work attainable from $\mathrm{gD}$ binding single instances of its receptors: The avidities of multiple $\mathrm{gD}$ protomers for HVEM, 3OSHS, and Nectin-1 can be calculated using the dissociation constants for gD:HVEM, 3.2 $\mu \mathrm{M}^{21,} 22,57$ gD:3OSHS, $2.0 \mu \mathrm{M},{ }^{27}$ and gD:Nectin-1, $17.1 \mathrm{nM}^{31}$ Transforming the overall dissociation constants via $\Delta_{r} G=$ $-k_{B} T \ln K_{D}$ gives the binding energies shown in Table 1 .

The minimum distance that $\mathrm{gB}$ would have to move in order to disrupt both leaflets of the cell membrane would be the width of the lipid bilayer, approximately $5 \mathrm{~nm}$. For two gD protomers to remain attached to two Nectin-1 molecules over this distance the transmissible force would be $31 \mathrm{pN}$. This force acting over the three points of contact of the crown of $\mathrm{gB}$ with the membrane, each approximately $2.4 \times$ 
$1.2 \mathrm{~nm}$ ellipses $2.26 \times 10^{-18} \mathrm{~m}^{2}$ in area, implies the maximum pressure exertable by $\mathrm{gB}$ in this case is $4.52 \mathrm{MPa}$. This pressure easily exceeds the $3 \mathrm{MPa}$ critical stress required to rupture a lipid bilayer, ${ }^{40}$ and is comparable to the ultimate tensile strength of skin, $20 \mathrm{MPa}{ }^{58}$ The real stress is likely to be higher during the configurational rearrangement of $\mathrm{gB}$, so these figures are lower estimates. The calculations mean the multipartite interaction between $\mathrm{gD}$ and its receptors would definitely hold the virion against the plasma membrane strongly enough to allow the $\mathrm{gB}$ spike to puncture it.

\begin{tabular}{|l|l|l|l|}
\hline Number of & Avidity as & Avidity as & Pressure \\
\hline gD:HVEM & $\mathrm{kD} / \mathrm{M}$ & $\mathrm{E} / \mathrm{zJ}$ & $\mathrm{P} / \mathrm{Mpa}$ \\
\hline 1 & $3.2 e-06$ & 54 & 1.60 \\
\hline 2 & $1.0 \mathrm{e}-11$ & 109 & 3.20 \\
\hline 3 & $3.3 \mathrm{e}-17$ & 163 & 4.80 \\
\hline $\mathrm{gD}: 3$ OSHS & $\mathrm{kD} / \mathrm{M}$ & $\mathrm{E} / \mathrm{zJ}$ & $\mathrm{P} / \mathrm{MPa}$ \\
\hline 1 & $2.0 e-06$ & 56 & 1.66 \\
\hline 2 & $4.0 \mathrm{e}-12$ & 113 & 3.32 \\
\hline 3 & $6.0 \mathrm{e}-18$ & 169 & 4.98 \\
\hline $\mathrm{gD}:$ Nectin & $\mathrm{kD} / \mathrm{M}$ & $\mathrm{E} / \mathrm{zJ}$ & $\mathrm{P} / \mathrm{Mpa}$ \\
\hline 1 & $1.7 e-08$ & 77 & 2.26 \\
\hline 2 & $2.9 \mathrm{e}-16$ & 153 & 4.52 \\
\hline 3 & $5.0 \mathrm{e}-24$ & 230 & 6.78 \\
\hline
\end{tabular}

Table 1. Avidities of gD binding its receptors translated to pressures exerted by $\mathbf{g B}$. Two or more complexes of $\mathrm{gD}$ with its receptors are usually necessary to allow disruption of both membrane leaflets by $\mathrm{gB}$ at $3 \mathrm{MPa}$, according to the calculations given in the main text.

The targeting of the virus to cholesterol-rich rafts by $\mathrm{gHgL}$ binding an $\alpha \mathrm{V} \beta 3$ integrin $^{43,44}$ and possibly by HSV-1 gB binding PILR $\alpha,{ }^{45-47,59}$ would also make a short, forceful movement more likely to achieve membrane puncture, because although membranes with a high percentage of cholesterol have high critical stress, they have low critical strain - the lowest local fractional change in area which causes rupture. ${ }^{40}$ For example, at $28 \%$ cholesterol the critical strain is 0.051 and the critical stress is $2.52 \mathrm{MPa}$ whereas at $78 \%$ cholesterol these values are 0.021 and $4.94 \mathrm{MPa}^{40}$ The stress $\mathrm{gB}$ can exert is calculated to exceed both critical stresses but a lower critical strain would assist it in puncturing the membrane. The likely activation of $\mathrm{gB}$ from its compact to its tall form by the profusion domain released when $\mathrm{gD}$ binds either HVEM or Nectin, ${ }^{28-30}$ means that $\mathrm{gB}$ is not activated until the plasma membrane of the cell is adjacent and held tightly against the virion by the binding of the viral antigens with their receptors. These aspects of the puncture mechanism are illustrated schematically in Fig. 2. Cell movement and virion surfing on filopodia, ${ }^{60}$ as well as bulk tissue distortion, would help the virus to tauten the section of cell membrane to which it had bound, by breaking and reforming binding interactions. For example, most HSV infections are orolabial HSV-1 infections at the vermillion border of the mouth, ${ }^{61}$ which is highly stretched and compressed during eating and speech. High tissue strain evidently assists HSV to establish bridgehead infections in cells that have tougher membranes than neurons because tensioning the section of bound membrane would also assist
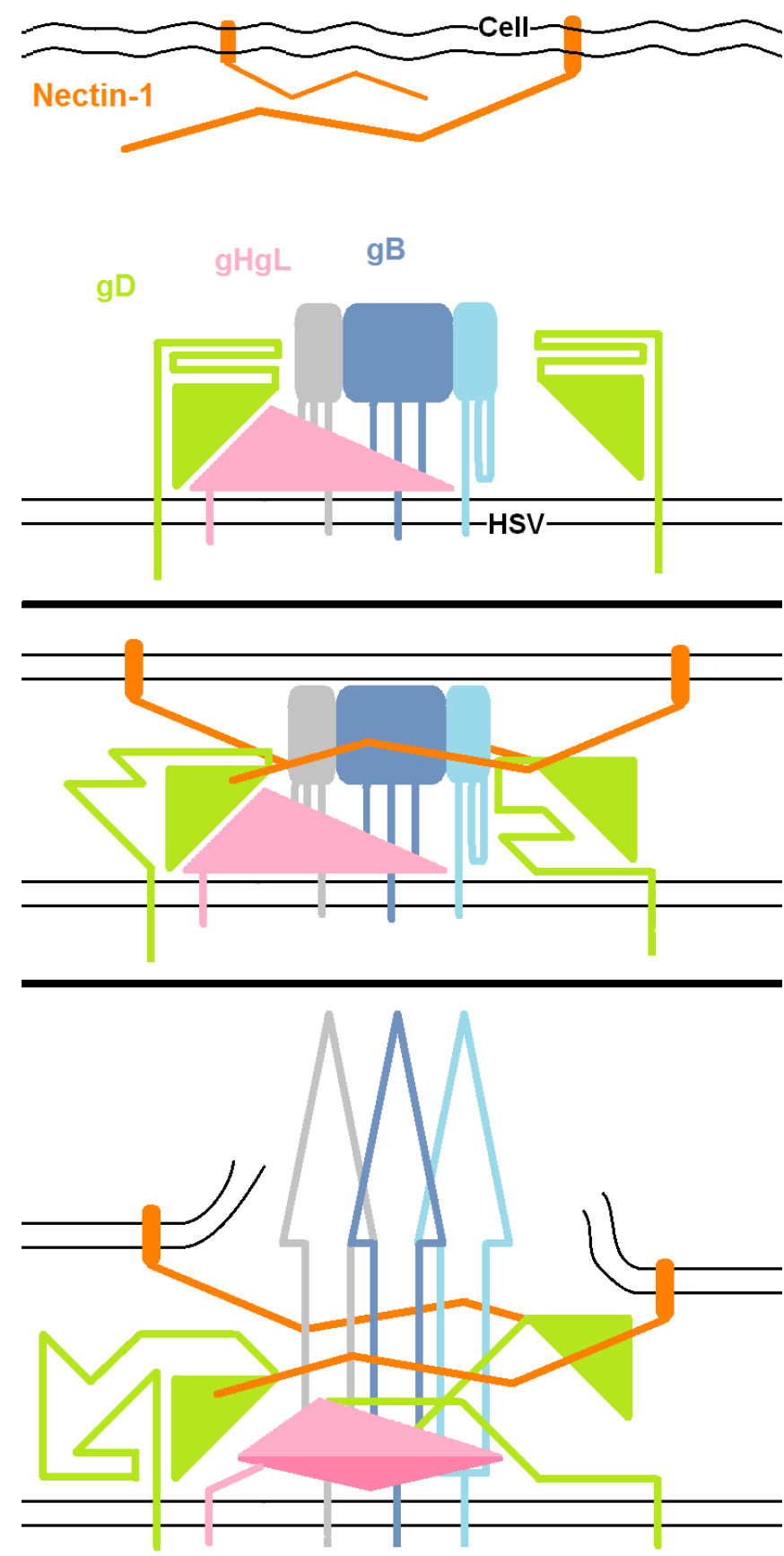

Figure 2. Schematic diagram of plasma membrane puncture by the essential HSV glycoproteins, leading to membrane fusion. Panel 1: None of the glycoproteins are bound to each other but steric interactions between them, and their anchorage to transmembrane and intravirion domains, hold down $\mathrm{gD}$ against $\mathrm{gHgL}$, preventing it from releasing $\mathrm{gB}$ from a high-energy metastable configuration. Panel 2: The binding of Nectin or HVEM to gD ensures the plasma membrane is adjacent and under tension and releases the disordered gD loop. Panel 3: When the profusion domain of a gD loop binds $\mathrm{gHgL}$ it triggers a conformational change in $\mathrm{gHgL}$ that then releases $\mathrm{gB}$ from its compact form, puncturing the plasma membrane. The binding interaction of $\mathrm{gD}$ protomers with HVEM, Nectin and/or 3-O Sulfated Heparan Sulfate is sufficient to hold the virion against the plasma membrane strongly enough for $\mathrm{gB}$ to puncture it. In the figure two $\mathrm{gD}$ protomers each bind Nectin. For clarity only one $\mathrm{gHgL}$ of three is shown.

$\alpha v \beta 6 / \alpha v \beta 8$ integrin-mediated endocytotic entry, ${ }^{38}$ once it becomes endosomal. Moreover, for entry at the plasma membrane of a neuron, if $\mathrm{gB}$ did not initially puncture it when springing up, then due to the complexation of $\mathrm{gD}$ with $\mathrm{gB}$ these forces could cause enough stress to do this subsequently. This point also applies if a compact form of $\mathrm{gB}$ does not exist. A related consideration for infection of 
epithelial tissue is that tissue distortion also breaks tight junctions between epithelial cells, which HSV virions could not otherwise traverse. ${ }^{62}$

Apart from ensuring it has closely and strongly bound the plasma membrane before activating $\mathrm{gB}$, the binding of the essential glycoproteins to their cellular receptors also induces a strengthening of the cytoskeleton by triggering the Phosphoinositide 3 kinase (PI3K) signaling cascade;, 63, 64 this results in the phosphorylation of cofilin, deactivating its depolymerization of F-actin. ${ }^{65}$ This pathway is mediated by extracellular signal-regulated kinase $(E R K)^{65}$ and the activation of Rho-associated, coiled-coil-containing protein kinase 1 (ROCK 1$)^{65-67}$. Artificially inhibiting these kinases allows cofilin to degrade actin and results in reduced infectivity. ${ }^{65}$ HSV-induced inhibition of actin depolymerization before entry strengthens the cytoskeleton and this would assist $\mathrm{gB}$ in puncturing the plasma membrane by providing a stiffer backing to push it against. A dense cytoskeleton would also prevent the cell from resealing the puncture itself by exocytotic fusion of lysosomes. ${ }^{68}$

\subsection{High electric field at membrane puncture would release the $\mathrm{gB}$ fusion domains}

The stable structure of the HSV fusion glycoprotein $\mathrm{gB}$ is a sturdy trimeric spike with a $16 \mathrm{~nm}$ tall ectodomain ${ }^{7,8}$ and two lipophilic fusion loop domains per protomer held in place by hydrogen bonds. ${ }^{69}$ These bonds are disrupted by reduced $\mathrm{pH}$ in endosomes. ${ }^{69}$ If $\mathrm{gB}$ were to transiently puncture the plasma membrane however, a very strong electric field would be produced - the $50 \mathrm{mV}$ membrane potential of a live cell dropped across the $5 \mathrm{~nm}$ thickness of the bilayer is a field strength of $10 \mathrm{MV} . \mathrm{m}^{-1}$. This electric field would also disrupt the hydrogen bonds and release the fusion loops, putting $\mathrm{gB}$ in its membrane fusion conformation as a direct physical consequence of puncturing the membrane. The lipophilic fusogen domains ${ }^{8}$ are in proximity to the envelope of the virion rather than further out, ${ }^{9}$ so it is possible that many other hydrogen bonds would be disrupted too, promoting the secondary structure to reform in the midst of the damaged bilayer. An alternative way to describe this process would be to say that, as protons are many times more mobile than other ions, the $\mathrm{pH}$ of the immediate locality would experience a sharp dip before any steady state ion current was established, and that this would disrupt the hydrogen bonds. In any case, completion of fusion is known to require another conformational change in $\mathrm{gB} ;^{70,71}$ its fusion domains must arc outwards to facilitate the initial expansion of the fusion pore. ${ }^{8,9}$

\subsection{The active forces triggered by the virus are all cell- retrograde}

The active cellular forces mentioned above are triggered by the interaction of the essential HSV glycoproteins with their cellular receptors. One example is the main receptor for HSV, Nectin-1. The structural relation of Nectin-1 to the cell is particularly strong, as its cytosolic side is tethered straight to the actin cytoskeleton via afadin. ${ }^{72}$ Even as a static anchor-point this marks its suitability for $\mathrm{gD}$ to bind to. However, gD binding Nectin-1 also induces its active internalization by the cell. ${ }^{36}$ Similarly, binding of HVEM by gD induces its internalization. ${ }^{73}$ Doses of cytochalasins B or $\mathrm{D}$, which prevent polymerization of actin filaments, ${ }^{74}$ reversibly inhibit HSV-1 entry to HEp-2 cells. ${ }^{75}$ It is not yet known whether HSV-1 also induces Syndecan internalisation though.

Apart from inducing HVEM internalization, $\mathrm{gD}$ also competes with an endogenous ligand called LIGHT $^{37}$ (Lymphotoxin-like Inducible protein that competes with Glycoprotein D for Herpes virus entry on $\mathbf{T}$ cells) that would otherwise induce endocytotic pathways in epithelia via myosin II regulatory light chain (MLC) phosphorylation. ${ }^{76}$ Thus gD binding HVEM also prevents the membrane from actively retreating.

Triggering of the internalization of the main $\mathrm{gD}$ receptors from the plasma membrane may be achieved by the binding of $\mathrm{gD}$ alone ${ }^{36,73}$ but might be assisted by the interaction of gB with PILR $\alpha$, because this promotes HSV-1 entry at the plasma membrane. ${ }^{77}$ For Nectin-1 the triggering event(s) may be the displacement by gD of other cis-bound Nectin-1 molecules, ${ }^{36}$ or the displacement of the $\alpha \mathrm{V} \beta 3$ integrin that also cis-binds the Nectin-1 ectodomain. ${ }^{36,78}$ Apart from gD binding 3OSHS, Nectin-1 and HVEM, the other two essential glycoproteins also form complexes with receptors capable of transducing signals to the cell, gHgL with $\alpha \mathrm{V} \beta 3$ and $\mathrm{gB}$ with PILR $\alpha$. Cytoskeletal rearrangements are also known to be triggered by ligands binding to integrins. ${ }^{43,79}$

Another important response to the HSV envelope binding is that the cell is induced to display a further raft-associated ${ }^{80 \text {, }}$ ${ }^{81}$ receptor for $\mathrm{gB}$, Non-muscle Myosin Heavy Chain IIA (NMHC-IIA). ${ }^{82}$ NMHC-IIA is usually intracellular, ${ }^{83}$ but can also be expressed in normal function on the cell surface $^{82,84}$ where it contributes to tissue architecture by controlled cell adhesion and active cell migration. ${ }^{83}$ Another name for NMHC-IIA is myosin 9, and this and myosin 6 are the only myosins known to walk towards the minus end of actin filaments (out of eighteen known classes). This retrograde transport, which in non-muscle cells is towards the interior, means that NMHC-IIA will actively pull gB towards the interior of these cells once triggered.

For cell lines without much membrane cholesterol, or with incorrect localization of $\alpha \mathrm{V} \beta 3$, entry at the plasma membrane (by puncture:fusion), would be less likely. On some cell types though, the above forces would be induced, and the pull from Nectin-1 and HVEM via $\mathrm{gD}$, and from NMHC-IIA/myosin 9 could pull the tall form of $\mathrm{gB}$ through the plasma membrane even if it had failed to do this when springing up from its compact form. This point would also apply to entry at the plasma membrane if the compact form of $\mathrm{gB}$ does not exist. In the total absence of entry at the plasma membrane on tough cells though, the interaction of gHgL with the $\alpha v \beta 6$ or $\alpha v \beta 8$ integrins, ${ }^{38}$ if present as for 
epithelial cells, can still mediate entry via various forms of endocytosis. $^{6,85-87}$

Once an endosome was detached from the membrane any forces exerted would generally move the entire endosome rather than pull the virion closer in to the membrane. The absence of membrane potential across an entirely intracellular endosome would require endosome acidification to reveal the $\mathrm{gB}$ fusion loops ${ }^{88,89}$ in place of the transient $\mathrm{pH}$ drop at the plasma membrane puncture point described above. Fusion with an endosomal membrane could still be influenced by membrane composition and fluctuations in mechanical stress inside the cell, which could explain the delay between endocytosis and capsid entry to cytoplasm $^{18}$ and the dependencies of fusion on ultraviolet light $^{90}$ or temperature ${ }^{91}$ and cell type. . $^{65,86,92}$

\section{Disrupting HSV entry}

\subsection{Reduced membrane tension}

The adhesion of $\mathrm{gC}$ to cell surface heparan sulfate is not absolutely required for virion entry but nevertheless greatly enhances its efficiency. ${ }^{93}$ According to the mechanism outlined above this is because it also plays a part in pretensioning the plasma membrane when it binds to its receptors. In this way, HSV-1 entry is significantly enhanced by the association of $\mathrm{gC}$ and $\mathrm{gB}$ with cell surface heparan sulfate. ${ }^{94}$

HSV entry into Vero and Hep2 cells occurs at the plasma membrane, ${ }^{86,}$ 95-97 but cholesterol-sequestering methylcyclodextrin inhibits HSV entry into Vero cells. ${ }^{98}$ In the context of the puncture:fusion hypothesis this is because the membrane is then less brittle, with a higher critical strain. Entry to keratinocytes also requires cholesterol. ${ }^{99}$ Finally, avidity-induced tensioning is consistent with the facts that soluble $\mathrm{gB}$ ectodomain binds cells and blocks entry, ${ }^{98}$ and that monoclonal antibodies for $\mathrm{gD}, \mathrm{gB}$ and $\mathrm{gH}$ all block viral penetration into the cell. ${ }^{100-102}$

In the absence of tissue strain on cultured cells, or due to reduced membrane tension, the molecular entry mechanism would occasionally stall at the state of hemifusion, where only the outer leaflets of the envelope and cell membrane are fused. Hemifusion cannot arise solely by apposition of the envelope bilayer with a cellular membrane because of strong repulsion due to hydration at gaps less than 2-3 $\mathrm{nm}^{103}$ that prevents direct contact, ${ }^{11,}{ }^{104}$ making membrane disruption by $\mathrm{gB}$ necessary for fusion and pore formation. The gB receptors PILR $\alpha$ and NMHC-IIA both enhance infectivity ${ }^{45,82}$ and may also function in this by their physical presence lowering the local critical stress of the cellular bilayer. This additional possibility is most evident from the lability of the display of NMHC-IIA. ${ }^{82,83}$

\subsection{Disruption of mechanism}

There are a range of results in the literature using soluble $\mathrm{gD}^{20,}{ }^{105-108}$ The truncated gDt construct only includes the
$\mathrm{gD}$ ectodomain and only mediates fusion if added after virions have bound to the cell surface. ${ }^{107}$ In this situation it still activates $\mathrm{gHgL}$ and hence $\mathrm{gB}$ only after it is next to the plasma membrane, and can even attach $\mathrm{gB}$ to the cytoskeleton, via gB-gDt-Nectin-Affadin, so this entry is expected. However, soluble gD added before virion attachment prevents infection rather than promoting it. ${ }^{106}$ In this scenario the opportunity to pre-tension the compact form of $\mathrm{gB}$ against the plasma membrane is totally lost: After binding an initial cellular receptor, gDt would release its profusion domain too early, activating $\mathrm{gB}$ as soon as it was in the vicinity and before it was close enough to puncture the plasma membrane during its conformational rearrangement.

Apart from the disruption of force transmission between $\mathrm{gD}$ and $\mathrm{gB}$, the cytoskeletal strengthening that the virus induces can also be disabled: The Cytochalasins B and D, which prevent polymerization of actin into microfilaments, ${ }^{74}$ reversibly inhibit HSV-1 entry to HEp-2 cells. ${ }^{75}$ This follows from the dismantling of the cytoskeleton that $\mathrm{gB}$ could otherwise push into and against to puncture the plasma membrane, which is necessary because it has very little surface tension of its own. ${ }^{109}$

\section{Structures of HSV entry}

\subsection{Deduction of a gB:gHgL:gD superstructure}

Viral fusogens usually have a compact, metastable conformation that stores energy required for membrane fusion. ${ }^{10-12}$ Although no such conformation for HSV gB has been crystallized, it now appears likely that it does actually exist but is just very unstable. ${ }^{14,110}$ Indeed, it has even been possible to reconstruct its probable structure by analogy with VSV G. ${ }^{13}$

Given only that fusion-competent $\mathrm{gB}$ is usually in a compact high-energy form somewhat similar to the recent reconstruction $^{13}$, and that this is so unstable, ${ }^{14,110}$ it would seem natural to think that $\mathrm{gHgL}$ initially binds $\mathrm{gB}$, keeping it compact, until $\mathrm{gD}$ destabilizes the complex and $\mathrm{gB}$ springs up and fuses the membranes. However, this would disagree with the evidence that $\mathrm{gHgL}$ is not initially bound to $\mathrm{gB}$ and only up-regulates $\mathrm{gB}$ function and binds to it having been activated itself by receptor-bound gD. ${ }^{29,} 30,111$ Instead, these latter facts suggest that $\mathrm{gHgL}$ only constrains the compact form of $\mathrm{gB}$ sterically, without binding it. This motivated me to look for a possible metastable superstructure of $\mathrm{gHgL}$ that could cage $\mathrm{gB}$. Because $\mathrm{gHgL}$ had been said not to form a trimer $^{15}$ the only plausible superstructure seemed to be a claw of three separate $\mathrm{gHgL}$ protomers reaching up around the compact form of $\mathrm{gB}$. This arrangement does not work though. However, an unstable tri-fold superstructure of $\mathrm{gHgL}$ could be stabilized by steric interactions, without strong enough binding interactions to make it a trimer on its own. Reasoning that to surround $\mathrm{gB}$ the size of a gap would have to be as large as possible, I projected to construct any possible tri-fold $\mathrm{gHgL}$ structure by maximizing the apparent 
cross-sectional area of its ectodomain then rotating two copies by 120 degrees in opposite directions and translating these to bring glycosylated residues close together without clashing any bonds. This arrangement worked very well, generating the gHgL triangle shown in Figs. 3 \& S1. This triangle is conjectured to be an unstable, high-energy configuration that can only be held in a metastable superstructure by steric interactions with the other essential glycoproteins. Three remarkable aspects to this structure are immediately apparent - Firstly, gB fits in the center perfectly as Fig. 3 illustrates. Secondly, one side of the $\mathrm{gHgL}$ triangle is very flat and has some glycosylated residues. Thirdly, there are three wedge-shaped spaces on the more irregular side that are also glycosylated.

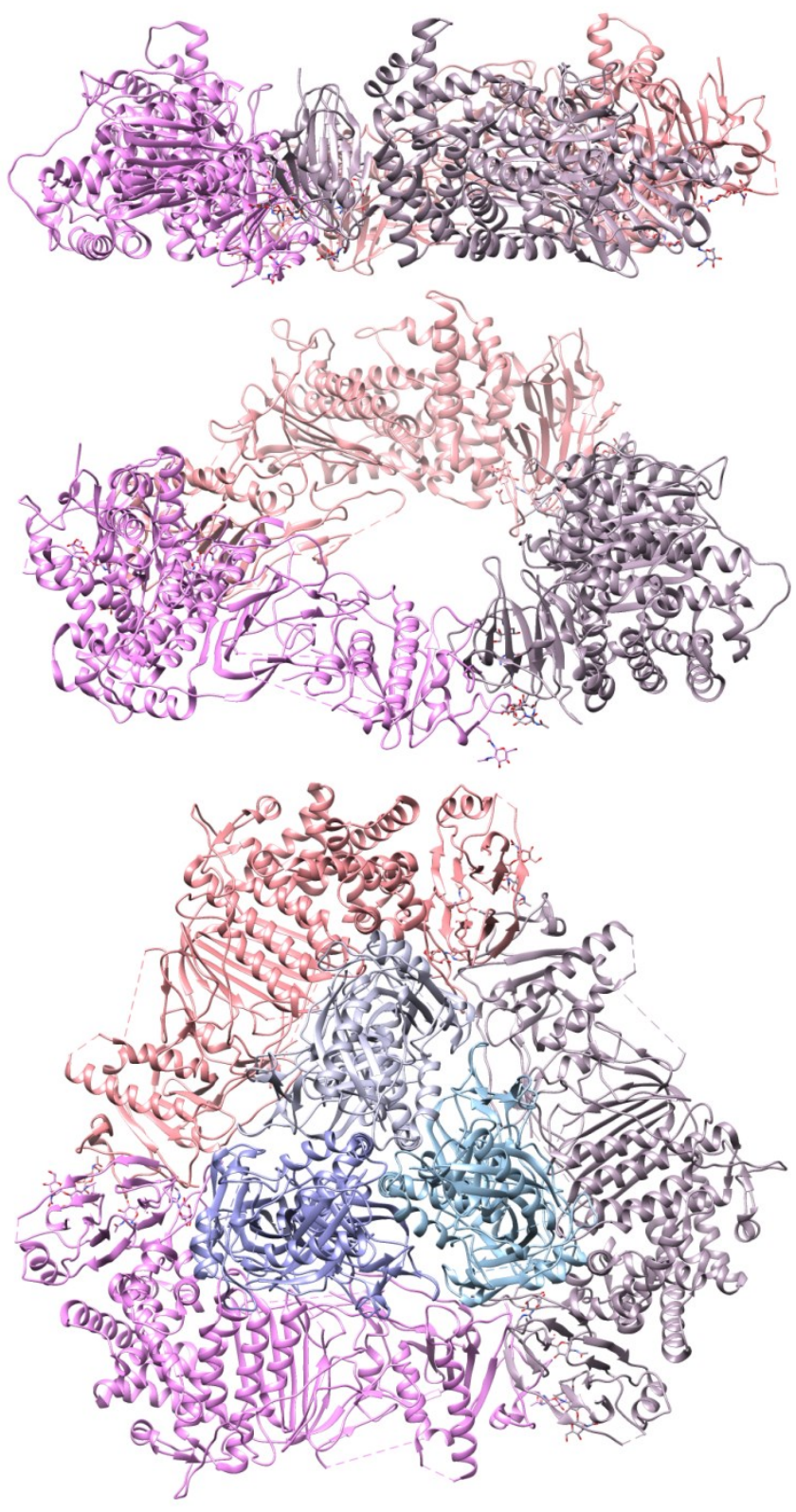

Figure 3. gHgL triangle. Three tessellated gHgL ectodomains; no stable binding interaction is implied: This is not a trimer. Side view: The lower face is very flat and displays glycosylated residues. Oblique angle view: Each side of the triangle has a glycosylated wedge-shaped gap. Top view: The structure is slightly interlocked like an impossible triangle. The wider, compact form of $\mathrm{gB}$ fits exactly inside the central gap, despite the fact that the triangle was pre-aligned without reference to it. $\mathrm{gHgL}$ is shown in magenta, pink and purple.
Two features of the gHgL triangle strongly indicate it is a native structure: Firstly, the central space of the $\mathrm{gHgL}$ triangle fits gB exactly. Secondly, its glycosylated side is extremely flat. This flatness of its glycosylated side indicates that it faces the virion membrane, which does not contradict the finding that $\mathrm{gHgL}$ does not bind to membranes, ${ }^{17}$ because it may be held down by something else. Structural alignment indicates that this is the function of $\mathrm{gD}$ : Single $\mathrm{gD}$ protomers fit in each of the three glycosylated spaces on the top of the $\mathrm{gHgL}$ triangle, with their n-acetyl-d-glucosamine (NAG) residues aligned between two gHgL NAG residues. In this position each $\mathrm{gD}$ pushes back against its partner protomer behind it while strongly anchored by its transmembrane region, ${ }^{48}$ thereby holding down each side of the triangular gHgL structure. $\mathrm{gD}$
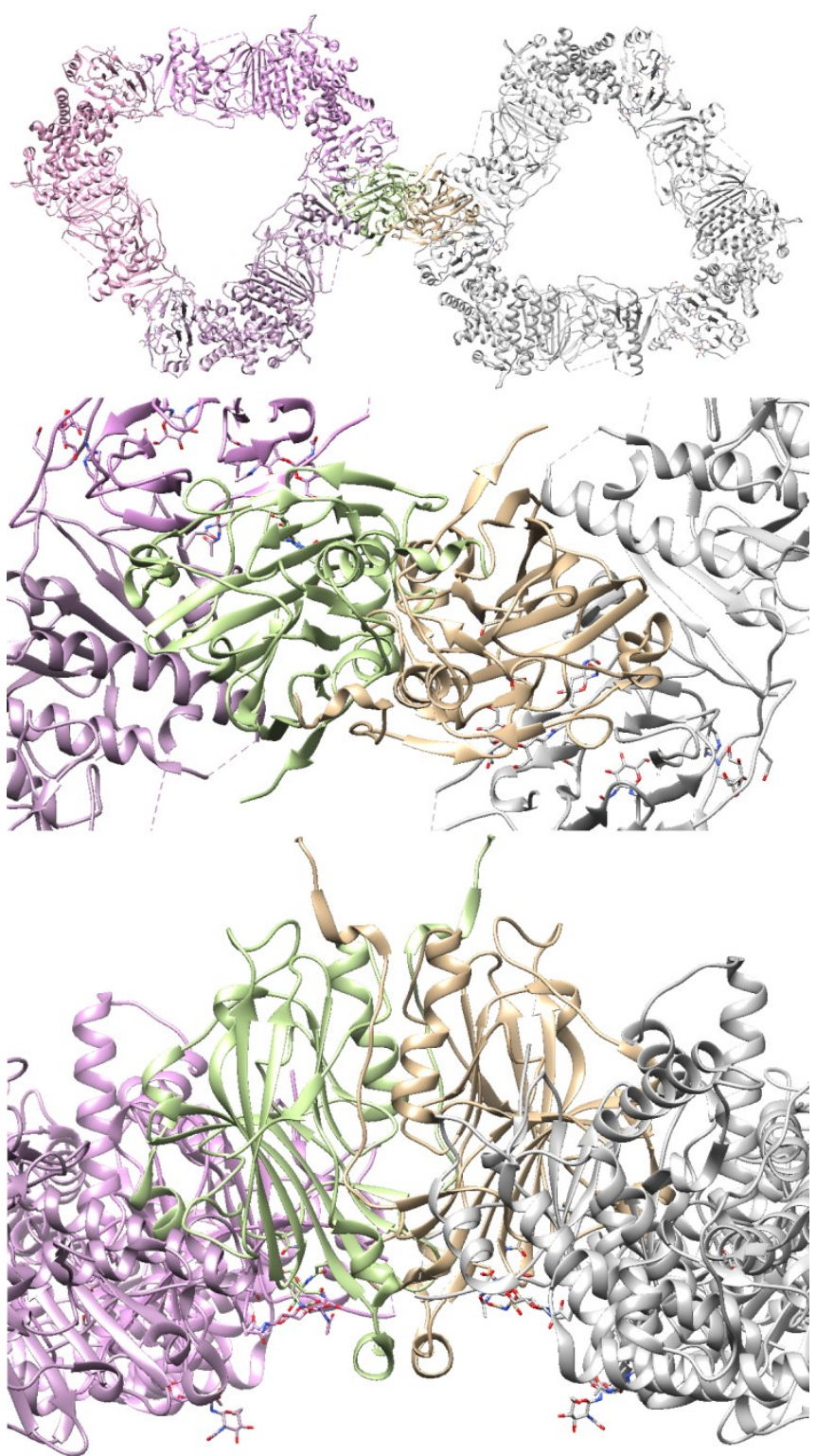

Figure 4. gD sterically locks the edges of gHgL triangles. Top: These superstructures tessellate hexagonally but leeway in the gD position may also allow pentagonal units. Zoom: The spaces in the $\mathrm{gHgL}$ triangle edges are the right size and shape for $\mathrm{gD}$ protomers. Interlocking in this way brings glycosylated residues together. Side view: Each gD pushes back against its partner locking the superstructure behind it and is tightly anchored to its transmembrane region until its linker is displaced. It is remarkable that the receptor binding regions are on the exposed top-half of the more crowded side of $\mathrm{gD}$. One $\mathrm{gHgL}$ triangle is shown in silver. 
is known to be dimeric on the virion surface. ${ }^{112}$ The configuration is illustrated in Figs. $4 \& 5$. It is possible to align $\mathrm{gD}$ to the space on $\mathrm{gHgL}$ using symmetry considerations: The back-to-back symmetry required for tessellation of these units constrains the axis of rotational symmetry of each gD dimer to be perpendicular to the local plane of the membrane, somewhat reducing the configurational space of possible orientations. Nevertheless, the flexibility of NAG alignment suggests there is enough leeway in the $\mathrm{gD}$ angle relative to $\mathrm{gHgL}$ to allow the units to tessellate in either hexagonal or pentagonal arrangements in order to accommodate the curvature of the virion surface. With $\mathrm{gD}$ in place, the unstructured region on top of $\mathrm{gHgL}^{17}$ might also contribute to stabilizing the $\mathrm{gHgL}$ triangle. It is

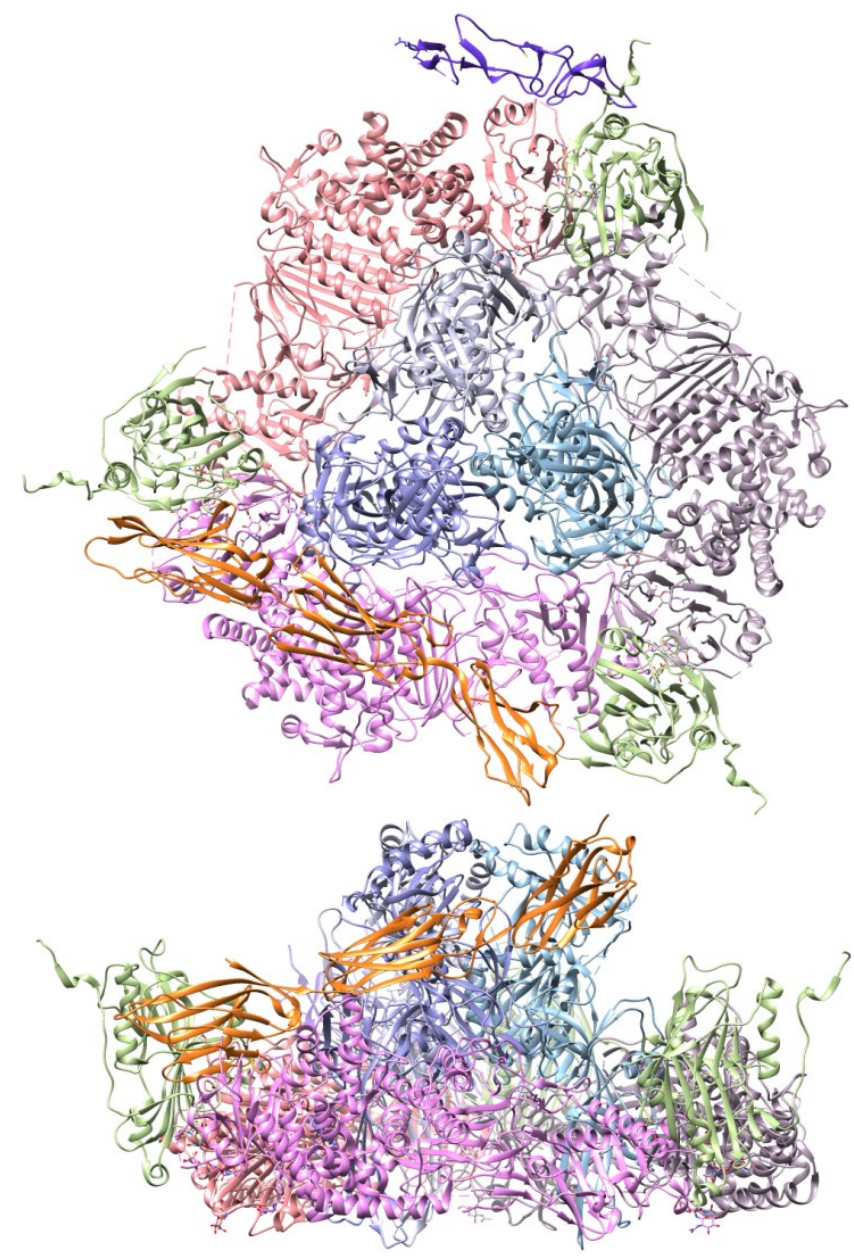

Figure 5. gD locks down gHgL around compact gB. The HSV receptors, HVEM (purple), Nectin (orange) and 3OSHS-Syndecan-2 bind gD without impinging on the rest of the superstructure (3OSHS is not shown but binds $\mathrm{gD}$ in a similar position to HVEM and Nectin). The bound gD structures were superposed with the unbound structures shown. No variation of the gD position was necessary. In binding the three $\mathrm{gD}$ molecules, its receptors displace the $\mathrm{gD}$ linkers, which allows the N-terminal $\mathrm{gD}$ domains to move away from each $\mathrm{gHgL}$, destabilizing the superstructure shown here.

possible that this part of $\mathrm{gHgL}$ only locks each protomer to its neighbor when $\mathrm{gD}$ is clamping it down. Thus there is no question that the free $\mathrm{gHgL}$ ectodomain would ever form a trimer - this triangular configuration is dependent on being held down on the membrane by its anchor-points, by three $\mathrm{gD}$ molecules and possibly also by the presence of the $\mathrm{gB}$ trimer at its center. Both steric and binding interactions that would immediately fall apart in solution could become quite strong locks once metastably anchored in such a superstructure. For example, in the $\mathrm{gD}$ dimer the loop holding an alpha helix of the other protomer could twist apart in solution, but in its native state the steric constraint of being anchored to the virion membrane would prevent this from happening until pulled upwards from one side by HVEM or Nectin as Fig. 5. indicates.

When displaced by HVEM or Nectin, the gD loop could disrupt the weak association of the glycosylated residues on the underside of $\mathrm{gHgL}$ with the virion membrane by binding its profusion domain to the top surface of $\mathrm{gHgL}$, inducing it to slightly arch away from the virion membrane and escaping any weak, short-range, attraction to it. This type of positional activation of $\mathrm{gHgL}$ is likely for the reasons set out in the next paragraph, which also suggest the gD PFD binds $\mathrm{gHgL}$ fusion region 1 (FR1). The gD loop is easily long enough to reach this binding region and still loop back to its transmembrane domain in the vicinity: The ordered structure of the $\mathrm{gD}$ ectodomain shown in the figures stops at residue 255 making a chain of 86 residues before the transmembrane domain begins at residue 341 . This loop would be $31 \mathrm{~nm}$ long and thereby reach up to $15 \mathrm{~nm}$ from the anchor-point when released, easily within range of binding regions on $\mathrm{gHgL}$ about $7 \mathrm{~nm}$ to the left of each $\mathrm{gD}$ protomer. These scales are illustrated by Fig. S2.

There is an important feature of the proposed triangular $\mathrm{gHgL}$ structure not yet mentioned: Aligning the crystal structures in this way results in the chain leading to the transmembrane region of each protomer pointing upwards, which would be away from the membrane. These residues are close to the gap available to $\mathrm{gD}$ and are visible in Figs. $3,4 \& 5$. In the initial, high-energy, superstructure these sections of each $\mathrm{gHgL}$ protomer, or its linker, would be strained to bend round through the edge of the central gap in the triangle to meet its transmembrane region. If $\mathrm{gD}$ primes $\mathrm{gHgL}$ to leave the membrane, this conformational strain would store the energy required to lift it away from the weak attraction between its glycosylated residues and the membrane, and would flip up the top side of each $\mathrm{gHgL}$ protomer towards $\mathrm{gB}$. For this to happen the residual attraction of $\mathrm{gHgL}$ to membrane would have to be too weak to stably bind to it, which is consistent with the finding that it does not bind membrane. ${ }^{17}$ There are three reasons for proposing that $\mathrm{gHgL}$ moves like this: Firstly, the bulky corner of each $\mathrm{gHgL}$ protomer would knock into the compact gB structure, contributing to its destabilization. Secondly, the FR1 binding region for $\mathrm{gB}$ is near this corner of $\mathrm{gHgL},{ }^{15,19}$ and adjusting the orientation of $\mathrm{gHgL}$ in this way does indeed align FR1 with a likely binding site near the base of the tall $\mathrm{gB}$ structure, as shown in Fig. 6. Thirdly, when all three $\mathrm{gHgL}$ protomers have flipped upwards, their fully open configuration seen in Fig. 6 would allow the three downward-pointing beta-hairpin loops of the compact form of $\mathrm{gB}$ to move anti-clockwise and open outwards, permitting $\mathrm{gB}$ to spring into its tall form. 
A spring-loaded movement of $\mathrm{gHgL}$ triggered by $\mathrm{gD}$ was modelled by pivoting each gHgL protomer about Leucine 790, highlighted in green in Fig. 6, on the anchored chain of $\mathrm{gHgL}$. This point is chosen because it is the first residue in the linker after a set of beta sheets, and is about mid-height in the crystal structure. FR1 appears to join a complementary region near the base of gB. If the $\mathrm{PFD}^{28}$ on the $\mathrm{gD}$ loop were to cause a structural transition in $\mathrm{gHgL}$ by binding to FR1 then in remaining attached there it could also enhance the avidity of FR1 for $\mathrm{gB}$. These ideas are fully consistent with the evidence that $\mathrm{gHgL}$ only binds $\mathrm{gB}$ in the presence of receptor-bound $\mathrm{gD}^{29,}, 30$ that the $\mathrm{gD} \mathrm{C}$-terminal chain is essential to entry, ${ }^{19-22}$ that it induces a structural transition in $\mathrm{gHgL}$ that enhances its affinity for $\mathrm{gB}^{28}$ and

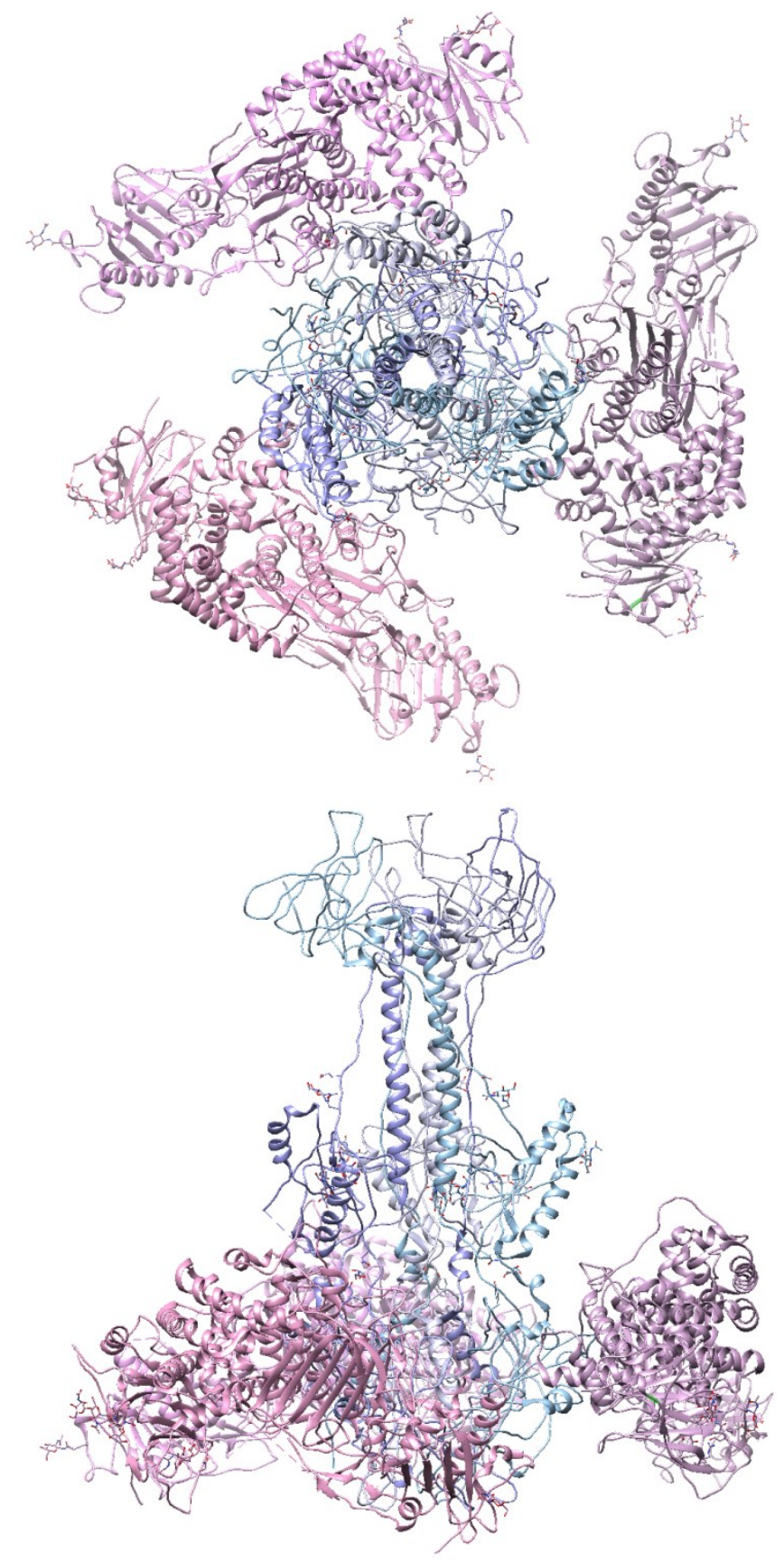

Figure 6. gHgL binds to the tall form of $\mathrm{gB}$. This open structure, now a super-complex due to the putative gHgL FR1 binding domain visible at lower right, does not restrict the $\mathrm{gB}$ fusion loops. The $\mathrm{gD}$ profusion domains would be clamped between the $\mathrm{gB}$ and $\mathrm{gHgL}$ binding domains. gHgL Leucine 790 is highlighted in green. remains bound to $\mathrm{gHgL}$ and $\mathrm{gB}$ in a supercomplex, ${ }^{28-30}$ and that the function of $\mathrm{gB}$ is regulated by activation of $\mathrm{gHgL}$ by receptor-bound $\mathrm{gD} .{ }^{111}$ With $\mathrm{gHgL}$ bound to it in this way, the tall conformation of $\mathrm{gB}$ is supported without its fusion domains being blocked in, which is consistent with the discussion in earlier sections. Finally, $\mathrm{gD}$ is very well anchored as we would expect for this mechanism: The intravirion domain of $\mathrm{gD}$ binds directly to the capsid, or via tegument protein VP22. ${ }^{113}$

Apart from the active cellular forces induced by the HSV antigens initially binding their receptors for endocytotic entry, puncturing the cell membrane also induces similar active responses. ${ }^{68,114}$ Therefore there is also a possibility that the gD PFD could transmit cellular forces on HVEM and/or Nectin to the tall form of gB, having already punctured the plasma membrane. The $\mathrm{gD}$ loop is integrally bonded to both its ectodomain bound to the $\mathrm{gD}$ receptors and to the membrane-spanning domain of $\mathrm{gD}$ attached to the capsid, ${ }^{113,115}$ so is ideally suited to transmit force. The PFD would also be pulling up on the gHgL transmembrane region and might even be able to pull it out to locally invert the virion envelope. This would clearly promote fusion of the virion and plasma membranes to a great extent.

This superstructure has probably not been identified experimentally yet because it is so large and unstable: Cross-linking studies would have discarded all groups of superstructures from initial centrifugations and the sample preparation required for electron micrographs would disrupt the superstructure. Super-resolution optical techniques require fluorophore labelling that would also disrupt it; for example a recent dSTORM study ${ }^{115}$ used the strongly neutralising LP2 antibody $^{116}$ that would displace the profusion domain from gD. ${ }^{35}$ Of all these techniques, superresolution microscopy using a non-neutralising FAB for $\mathrm{gHgL}$ may stand the best chance of verifying an initial triangular configuration for it in future studies. The structure could then be qualified as a native structure after optical examination by assaying the same virions for infectivity.

\subsection{The virion surface}

Electron tomography of cryogenically frozen HSV virions indicates they are $225 \mathrm{~nm}$ in diameter and have 600-750 spikes on the surface. ${ }^{117}$ The surface spikes were not very well resolved compared to the reconstruction of the capsid. Assuming the preparation and freezing process disrupts any superstructures then the spikes counted would only generally represent the larger glycoproteins, $\mathrm{gB}$ and $\mathrm{gHgL}$. We can estimate what proportion these are of the spikes counted using the single-molecule fluorescence determination of the $\mathrm{gD}$ copy number per virion at $335 \mathrm{*} /$ 0.7. ${ }^{118}$ This would indicate the number of superstructures originally on the surface was approximately 112, making the expected number of $\mathrm{gB}$ and $\mathrm{gHgL}$ spikes 448. This is approximately two-thirds of the spikes counted. The agreement of these estimations allows us to estimate the proportion of the virion surface occupied by the 
gB:gHgL:gD superstructures. A virion of $225 \mathrm{~nm}$ diameter would have a surface area of $1.59 \times 10^{-13} \mathrm{~m}^{2}$. The distance between adjacent centers of the superstructures is $15 \mathrm{~nm}$, implying the triangular space they each occupy has a width of $22.5 \mathrm{~nm}$ and a base of $26 \mathrm{~nm}$. Thus the area needed by each superstructure is $2.93 \times 10^{-16} \mathrm{~m}^{2}$ and the area required for 112 of them is approximately $3.28 \times 10^{-14} \mathrm{~m}^{2}, 20.6 \%$ of the total surface area of the virion. Accounting for the variation in $\mathrm{gD}$ copy number this would be $14.4 \%-20.6 \%$ $29.4 \%$ of the virion surface. These seem quite low percentages but the virion surface does usually accommodate many other types of glycoproteins, including UL32, UL49A, gM, gC, gE, gI, gJ, and gK, so a surface area fraction of $14-29 \%$ for the $\mathrm{gB}: \mathrm{gHgL}: \mathrm{gD}$ superstructure is probably realistic.

\section{Structural alignments}

The structural alignments presented in the figures, made using UCSF Chimera, ${ }^{119}$ are not computationally optimized and should only be viewed as detailed cartoons showing symmetries and approximate tessellations. Because the initial metastable superstructure is conjectured only to be locked by steric interactions, rather than binding interactions, future optimization by energy minimization would have to allow for potential energy storage by antibinding, and for the strains and forces on transmembrane regions. This level of modelling is beyond our resources, but no like-charged residues are adjacent in the tessellations.

The structures used for alignment and figures were as follows; codes are PDB ID references: $\mathrm{gB}$ ectodomain, compact form. ${ }^{13} \mathrm{gB}$ ectodomain, tall form: $3 \mathrm{NW} 8 \& \mathrm{gB}$ ectodomain, fusogenic form: $3 \mathrm{NWF}^{69} \mathrm{gHgL}$ ectodomain: 3M1C. ${ }^{17} \mathrm{gD}$ ectodomain, no disordered loop: $1 \mathrm{~L} 2 \mathrm{G} \& \mathrm{gD}$ ectodomain bound to HVEM: $1 \mathrm{JMA}^{26} \mathrm{gD}$ ectodomain bound to Nectin-1: $3 \mathrm{U} 82$. $^{31}$

\section{Summary of the full membrane-fusion hypothesis}

Binding a cell-surface receptor displaces the gD loop whose profusion domain binds to $\mathrm{gHgL}$ FR1, triggering a springloaded movement of $\mathrm{gHgL}$ from a metastable membraneassociated conformation that was sterically stabilizing a compact form of $\mathrm{gB}$. This directed movement of $\mathrm{gHgL}$ brings FR1 into contact with a binding region on the tall form of $\mathrm{gB}$, where its avidity is enhanced by the $\mathrm{gD}$ profusion domain clamped between them. In this way a sterically metastable superstructure of $\mathrm{gD}, \mathrm{gHgL}$ and $\mathrm{gB}$ is pre-tensioned against the most brittle areas of the plasma membrane by receptor binding before $\mathrm{gB}$ is activated from its compact to its tall conformation, during which it would often puncture the plasma membrane. This would generate a brief and local drop in $\mathrm{pH}$ due to the membrane potential and the high mobility of protons in water. The drop in $\mathrm{pH}$ would trigger another slight conformational rearrangement of $\mathrm{gB}$ that releases its fusion domains, allowing them to embed in both leaflets of the plasma membrane, mediating its fusion with the virion envelope. Formation of the full fusion pore follows. Membrane puncture and fusion would be assisted by bulk tissue strain further tensioning $\mathrm{gB}$ against the plasma membrane and by virion-induced strengthening of the cytoskeleton. On some tougher cell types the virion induces its endocytosis having failed to puncture the plasma membrane by the activation of $\mathrm{gB}$. In this alternative entry pathway the virion then remains in a pre-tensioned state in an endosome until mechanical fluctuations may eventually induce fusion. The activation energy for endosomal entry would be lowered by vesicular acidification revealing the fusion loops of $\mathrm{gB}$.

\section{Conclusions}

This paper presents various physical considerations relevant to HSV entry and its disruption, and proposes a functional, sterically metastable, superstructure for the essential glycoproteins. The main conceptual result is that $\mathrm{gD}$ binds its receptors strongly enough to hold $\mathrm{gB}$ against the plasma membrane with enough force to puncture it during its activation. The principal targets of HSV are neurons because there it can maintain latent infection for the full life of the organism. On less brittle cells gB cannot puncture the membrane in the first instance but on some cell types retrograde forces induced in the cell endocytose the virion. This leads to entry when endosome acidification breaks the hydrogen bonds securing the fusion loops of $\mathrm{gB}$. In the optimized entry pathway to neurons, this paper has argued that these hydrogen bonds would also be broken when the activated fusogen is suddenly exposed to a high local electric field after transiently puncturing the live plasma membrane, leading to membrane fusion.

Overall, there is now a physical and structural basis for the result that a single $\mathrm{gD}$ can support HSV entry. 34,35 Physically, gD has enough receptor avidity to assist $\mathrm{gB}$ in puncturing a brittle plasma membrane by holding it against the fusogen during its rearrangement. Structurally, we have seen that only one $\mathrm{gD}$ is required to hold down each $\mathrm{gHgL}$ heterodimer sterically stabilizing the compact form of $\mathrm{gB}$.

\section{Publication Notes}

This manuscript is as accepted after peer review; see DOI 10.1021/acsinfecdis.5b00059 for the version typeset by the journal. (C)American Chemical Society. *rwc25ロcamªc ${ }^{\circ} u k$

\section{Acknowledgements}

I am grateful for comments from Drs. H. Browne, Y. Modis and T. D. C. Thomas, and from Professors M. Stanley, D. Klenerman, and A. Minson, and to the RSCB PDB, ${ }^{120}$ and the UCSF RBVI. ${ }^{119}$ I acknowledge a research fellowship at Christ's College, Cambridge, U.K.

\section{References}

(1) Cai, W. H., Gu, B., and Person, S. (1988) Role of glycoprotein $\mathrm{B}$ of herpes simplex virus type 1 in viral entry and cell fusion, J. Virol. 62, 2596-2604. 
(2) Forrester, A., Farrell, H., Wilkinson, G., Kaye, J., Davis-Poynter, N., and Minson, T. (1992) Construction and properties of a mutant of herpes simplex virus type 1 with glycoprotein H coding sequences deleted, J. Virol. 66, 341348.

(3) Ligas, M. W., and Johnson, D. C. (1988) A herpes simplex virus mutant in which glycoprotein D sequences are replaced by beta-galactosidase sequences binds to but is unable to penetrate into cells, J. Virol. 62, 1486-1494.

(4) Roop, C., Hutchinson, L., and Johnson, D. C. (1993) A Mutant Herpes-Simplex Virus Type-1 Unable to Express Glycoprotein-L Cannot Enter Cells, and Its Particles Lack Glycoprotein-H, J. Virol. 67, 2285-2297.

(5) Turner, A., Bruun, B., Minson, T., and Browne, H. (1998) Glycoproteins gB, gD, and gHgL of herpes simplex virus type 1 are necessary and sufficient to mediate membrane fusion in a Cos cell transfection system, J. Virol. $72,873-875$.

(6) Nicola, A. V., and Straus, S. E. (2004) Cellular and viral requirements for rapid endocytic entry of herpes simplex virus, J. Virol. 78, 7508-7517. DOI: 10.1128/JVI.78.14.7508-7517.2004.

(7) Stannard, L. M., Fuller, A. O., and Spear, P. G. (1987) Herpes simplex virus glycoproteins associated with different morphological entities projecting from the virion envelope, J. Gen. Virol. 68 ( Pt 3), 715-725.

(8) Heldwein, E. E., Lou, H., Bender, F. C., Cohen, G. H., Eisenberg, R. J., and Harrison, S. C. (2006) Crystal structure of glycoprotein B from herpes simplex virus 1, Science 313, 217-220. DOI: 10.1126/science. 1126548 .

(9) Hannah, B. P., Cairns, T. M., Bender, F. C., Whitbeck, J. C., Lou, H., Eisenberg, R. J., and Cohen, G. H. (2009) Herpes simplex virus glycoprotein $\mathrm{B}$ associates with target membranes via its fusion loops, J. Virol. 83, 6825-6836. DOI: 10.1128/JVI.00301-09.

(10) White, J. M., Delos, S. E., Brecher, M., and Schornberg, K. (2008) Structures and mechanisms of viral membrane fusion proteins: multiple variations on a common theme, Crit. Rev. Biochem. Mol. Biol. 43, 189-219. DOI: 10.1080/10409230802058320.

(11) Harrison, S. C. (2008) Viral membrane fusion, Nat. Struct. Mol. Biol. 15, 690-698. DOI: 10.1038/nsmb.1456.

(12) Eckert, D. M., and Kim, P. S. (2001) Mechanisms of viral membrane fusion and its inhibition, Annu. Rev. Biochem. 70, 777-810. 10.1146/annurev.biochem.70.1.777.

(13) Gallagher, J. R., Atanasiu, D., Saw, W. T., Paradisgarten, M. J., Whitbeck, J. C., Eisenberg, R. J., and Cohen, G. H. (2014) Functional Fluorescent Protein Insertions in Herpes Simplex Virus gB Report on gB Conformation before and after Execution of Membrane Fusion, PLoS Pathog. 10, e1004373. DOI: 10.1371/journal.ppat.1004373 ARTN e1004373

(14) Vitu, E., Sharma, S., Stampfer, S. D., and Heldwein, E. E. (2013) Extensive mutagenesis of the HSV-1 gB ectodomain reveals remarkable stability of its postfusion form, J. Mol. Biol. 425, 2056-2071. DOI: 10.1016/j.jmb.2013.03.001.

(15) Eisenberg, R. J., Atanasiu, D., Cairns, T. M., Gallagher, J. R., Krummenacher, C., and Cohen, G. H. (2012) Herpes virus fusion and entry: a story with many characters, Viruses 4, 800-832. DOI: 10.3390/v4050800.

(16) Hutchinson, L., Browne, H., Wargent, V., DavisPoynter, N., Primorac, S., Goldsmith, K., Minson, A. C., and Johnson, D. C. (1992) A novel herpes simplex virus glycoprotein, gL, forms a complex with glycoprotein $\mathrm{H}(\mathrm{gH})$ and affects normal folding and surface expression of $\mathrm{gH}, J$. Virol. 66, 2240-2250.

(17) Chowdary, T. K., Cairns, T. M., Atanasiu, D., Cohen, G. H., Eisenberg, R. J., and Heldwein, E. E. (2010) Crystal structure of the conserved herpesvirus fusion regulator complex gH-gL, Nat. Struct. Mol. Biol. 17, 882-888. DOI: 10.1038/nsmb.1837.

(18) Eisenberg, R. J., Heldwein, E. E., Cohen, G. H., and Krummenacher, C. (2011) Recent progress in understanding herpes simplex virus entry: relationship of structure to function., In Alphaherpesviruses : molecular virology (Weller, S. K., Ed.), pp 131-152, Caister Academic Press, Norfolk, UK.

(19) Chiang, H. Y., Cohen, G. H., and Eisenberg, R. J. (1994) Identification of functional regions of herpes simplex virus glycoprotein $\mathrm{gD}$ by using linker-insertion mutagenesis, J. Virol. 68, 2529-2543.

(20) Nicola, A. V., Willis, S. H., Naidoo, N. N., Eisenberg, R. J., and Cohen, G. H. (1996) Structure-function analysis of soluble forms of herpes simplex virus glycoprotein D, $J$. Virol. 70, 3815-3822.

(21) Rux, A. H., Willis, S. H., Nicola, A. V., Hou, W., Peng, C., Lou, H., Cohen, G. H., and Eisenberg, R. J. (1998) Functional region IV of glycoprotein D from herpes simplex virus modulates glycoprotein binding to the herpesvirus entry mediator, J. Virol. 72, 7091-7098.

(22) Willis, S. H., Rux, A. H., Peng, C., Whitbeck, J. C., Nicola, A. V., Lou, H., Hou, W., Salvador, L., Eisenberg, R. J., and Cohen, G. H. (1998) Examination of the kinetics of herpes simplex virus glycoprotein $\mathrm{D}$ binding to the herpesvirus entry mediator, using surface plasmon resonance, J. Virol. 72, 5937-5947.

(23) Fusco, D., Forghieri, C., and Campadelli-Fiume, G. (2005) The pro-fusion domain of herpes simplex virus glycoprotein $\mathrm{D}(\mathrm{gD})$ interacts with the $\mathrm{gD} \mathrm{N}$ terminus and is displaced by soluble forms of viral receptors, Proc. Natl. Acad. Sci. U. S. A. 102, 9323-9328. DOI: 10.1073/pnas.0503907102.

(24) Krummenacher, C., Supekar, V. M., Whitbeck, J. C., Lazear, E., Connolly, S. A., Eisenberg, R. J., Cohen, G. H., Wiley, D. C., and Carfi, A. (2005) Structure of unliganded HSV gD reveals a mechanism for receptor-mediated activation of virus entry, EMBO J. 24, 4144-4153. DOI: 10.1038/sj.emboj.7600875.

(25) Bacsa, S., Karasneh, G., Dosa, S., Liu, J., Valyi-Nagy, T., and Shukla, D. (2011) Syndecan-1 and syndecan-2 play key roles in herpes simplex virus type-1 infection, J. Gen. Virol. 92, 733-743.

(26) Carfi, A., Willis, S. H., Whitbeck, J. C., Krummenacher, C., Cohen, G. H., Eisenberg, R. J., and Wiley, D. C. (2001) Herpes simplex virus glycoprotein D bound to the human receptor HveA, Mol. Cell 8, 169-179.

(27) Shukla, D., Liu, J., Blaiklock, P., Shworak, N. W., Bai, X., Esko, J. D., Cohen, G. H., Eisenberg, R. J., Rosenberg, R. D., and Spear, P. G. (1999) A novel role for 3-O-sulfated heparan sulfate in herpes simplex virus 1 entry, Cell 99, 1322.

(28) Gianni, T., Amasio, M., and Campadelli-Fiume, G. (2009) Herpes simplex virus gD forms distinct complexes with fusion executors $\mathrm{gB}$ and $\mathrm{gH} / \mathrm{gL}$ in part through the Cterminal profusion domain, J. Biol. Chem. 284, 1737017382. DOI: 10.1074/jbc.M109.005728.

(29) Atanasiu, D., Whitbeck, J. C., Cairns, T. M., Reilly, B., Cohen, G. H., and Eisenberg, R. J. (2007) Bimolecular complementation reveals that glycoproteins $\mathrm{gB}$ and $\mathrm{gH} / \mathrm{gL}$ of herpes simplex virus interact with each other during cell 
fusion, Proc. Natl. Acad. Sci. U. S. A. 104, 18718-18723. DOI: $10.1073 /$ pnas.0707452104.

(30) Avitabile, E., Forghieri, C., and Campadelli-Fiume, G. (2007) Complexes between herpes simplex virus glycoproteins $\mathrm{gD}, \mathrm{gB}$, and $\mathrm{gH}$ detected in cells by complementation of split enhanced green fluorescent protein, J. Virol. 81, 11532-11537. DOI: 10.1128/JVI.01343-07.

(31) Zhang, N., Yan, J., Lu, G., Guo, Z., Fan, Z., Wang, J., Shi, Y., Qi, J., and Gao, G. F. (2011) Binding of herpes simplex virus glycoprotein D to nectin-1 exploits host cell adhesion, Nat. Commun. 2, 577. DOI: 10.1038/ncomms 1571 .

(32) Pauling, L., and Corey, R. B. (1951) The pleated sheet, a new layer configuration of polypeptide chains, Proc. Natl. Acad. Sci. U. S. A. 37, 251-256.

(33) McGeoch, D. J., Dolan, A., Donald, S., and Rixon, F. J. (1985) Sequence determination and genetic content of the short unique region in the genome of herpes simplex virus type 1, J. Mol. Biol. 181, 1-13.

(34) Huber, M. T., Wisner, T. W., Hegde, N. R., Goldsmith, K. A., Rauch, D. A., Roller, R. J., Krummenacher, C., Eisenberg, R. J., Cohen, G. H., and Johnson, D. C. (2001) Herpes simplex virus with highly reduced gD levels can efficiently enter and spread between human keratinocytes, $J$. Virol. 75, 10309-10318. DOI: 10.1128/Jvi.75.21.1030910318.2001.

(35) Clarke, R. W., Drews, A., Browne, H., and Klenerman, D. (2013) A single gD glycoprotein can mediate infection by Herpes Simplex virus, J. Am. Chem. Soc. 135, 11175-11180. DOI: $10.1021 / \mathrm{ja} 4038406$.

(36) Stiles, K. M., and Krummenacher, C. (2010) Glycoprotein D actively induces rapid internalization of two nectin-1 isoforms during herpes simplex virus entry, Virology 399, 109-119. DOI: 10.1016/j.virol.2009.12.034.

(37) Mauri, D. N., Ebner, R., Montgomery, R. I., Kochel, K. D., Cheung, T. C., Yu, G. L., Ruben, S., Murphy, M., Eisenberg, R. J., Cohen, G. H., Spear, P. G., and Ware, C. F. (1998) LIGHT, a new member of the TNF superfamily, and lymphotoxin alpha are ligands for herpesvirus entry mediator, Immunity 8, 21-30.

(38) Gianni, T., Salvioli, S., Chesnokova, L. S., HuttFletcher, L. M., and Campadelli-Fiume, G. (2013) $\alpha v \beta 6$-and $\alpha v \beta 8$-integrins serve as interchangeable receptors for HSV $\mathrm{gH} / \mathrm{gL}$ to promote endocytosis and activation of membrane fusion, PLoS Pathog. 9, e1003806. DOI: 10.1371/journal.ppat.1003806.

(39) Nicola, A. V., Hou, J., Major, E. O., and Straus, S. E. (2005) Herpes simplex virus type 1 enters human epidermal keratinocytes, but not neurons, via a $\mathrm{pH}$-dependent endocytic pathway, J. Virol. 79, 7609-7616. DOI: 10.1128/JVI.79.12.7609-7616.2005.

(40) Needham, D., and Nunn, R. S. (1990) Elastic deformation and failure of lipid bilayer membranes containing cholesterol, Biophys. J. 58, 997-1009. DOI: 10.1016/S0006-3495(90)82444-9.

(41) Herold, B. C., Visalli, R. J., Susmarski, N., Brandt, C. R., and Spear, P. G. (1994) Glycoprotein C-independent binding of herpes simplex virus to cells requires cell surface heparan sulphate and glycoprotein B, J. Gen. Virol. 75, 1211-1222.

(42) Rux, A. H., Lou, H., Lambris, J. D., Friedman, H. M., Eisenberg, R. J., and Cohen, G. H. (2002) Kinetic analysis of glycoprotein $\mathrm{C}$ of herpes simplex virus types 1 and 2 binding to heparin, heparan sulfate, and complement component C3b, Virology 294, 324-332. DOI: 10.1006/viro.2001.1326.

(43) Parry, C., Bell, S., Minson, T., and Browne, H. (2005) Herpes simplex virus type 1 glycoprotein $\mathrm{H}$ binds to alphavbeta3 integrins, J. Gen. Virol. 86, 7-10. DOI: 10.1099/vir.0.80567-0.

(44) Gianni, T., Gatta, V., and Campadelli-Fiume, G. (2010) $\alpha V \beta 3$-integrin routes herpes simplex virus to an entry pathway dependent on cholesterol-rich lipid rafts and dynamin2, Proc. Natl. Acad. Sci. U. S. A. 107, 22260-22265. DOI: $10.1073 /$ pnas.1014923108.

(45) Satoh, T., Arii, J., Suenaga, T., Wang, J., Kogure, A., Uehori, J., Arase, N., Shiratori, I., Tanaka, S., Kawaguchi, Y., Spear, P. G., Lanier, L. L., and Arase, H. (2008) PILRalpha is a herpes simplex virus-1 entry coreceptor that associates with glycoprotein B, Cell 132, 935-944. DOI: 10.1016/j.cell.2008.01.043.

(46) Shukla, S. Y., Singh, Y. K., and Shukla, D. (2009) Role of nectin-1, HVEM, and PILR-alpha in HSV-2 entry into human retinal pigment epithelial cells, Invest. Ophthalmol. Visual Sci. 50, 2878-2887. DOI: 10.1167/iovs.08-2981.

(47) Fan, Q., and Longnecker, R. (2010) The Ig-like v-type domain of paired Ig-like type 2 receptor alpha is critical for herpes simplex virus type 1 -mediated membrane fusion, $J$. Virol. 84, 8664-8672. DOI: 10.1128/JVI.01039-10.

(48) Browne, H., Bruun, B., Whiteley, A., and Minson, T. (2003) Analysis of the role of the membrane-spanning and cytoplasmic tail domains of herpes simplex virus type 1 glycoprotein D in membrane fusion, J. Gen. Virol. 84, 10851089.

(49) Zago, A., Jogger, C. R., and Spear, P. G. (2004) Use of herpes simplex virus and pseudorabies virus chimeric glycoprotein D molecules to identify regions critical for membrane fusion, Proc. Natl. Acad. Sci. U. S. A. 101, 17498-17503. DOI: 10.1073/pnas.0408186101.

(50) Lazear, E., Carfi, A., Whitbeck, J. C., Cairns, T. M., Krummenacher, C., Cohen, G. H., and Eisenberg, R. J. (2008) Engineered disulfide bonds in herpes simplex virus type $1 \mathrm{gD}$ separate receptor binding from fusion initiation and viral entry, J. Virol. 82, 700-709. DOI: 10.1128/JVI.02192-07.

(51) Di Giovine, P., Settembre, E. C., Bhargava, A. K., Luftig, M. A., Lou, H., Cohen, G. H., Eisenberg, R. J., Krummenacher, C., and Carfi, A. (2011) Structure of herpes simplex virus glycoprotein D bound to the human receptor nectin-1, PLoS Pathog. 7, e1002277. DOI: 10.1371/journal.ppat.1002277.

(52) Narita, H., Yamamoto, Y., Suzuki, M., Miyazaki, N., Yoshida, A., Kawai, K., Iwasaki, K., Nakagawa, A., Takai, Y., and Sakisaka, T. (2011) Crystal Structure of the cisDimer of Nectin-1: implications for the architecture of cellcell junctions, J. Biol. Chem. 286, 12659-12669. DOI: 10.1074/jbc.M110.197368.

(53) Liu, J., and Thorp, S. C. (2002) Cell surface heparan sulfate and its roles in assisting viral infections, Med. Res. Rev. 22, 1-25.

(54) Liu, J., Shriver, Z., Pope, R. M., Thorp, S. C., Duncan, M. B., Copeland, R. J., Raska, C. S., Yoshida, K., Eisenberg, R. J., and Cohen, G. (2002) Characterization of a heparan sulfate octasaccharide that binds to herpes simplex virus type 1 glycoprotein D, J. Biol. Chem. 277, 3345633467.

(55) Tumova, S., Woods, A., and Couchman, J. R. (2000) Heparan sulfate chains from glypican and syndecans bind 
the Hep II domain of fibronectin similarly despite minor structural differences, J. Biol. Chem. 275, 9410-9417.

(56) Volk, R., Schwartz, J. J., Li, J., Rosenberg, R. D., and Simons, M. (1999) The role of syndecan cytoplasmic domain in basic fibroblast growth factor-dependent signal transduction, J. Biol. Chem. 274, 24417-24424.

(57) Connolly, S. A., Landsburg, D. J., Carfi, A., Wiley, D. C., Eisenberg, R. J., and Cohen, G. H. (2002) Structurebased analysis of the herpes simplex virus glycoprotein D binding site present on herpesvirus entry mediator HveA (HVEM), J. Virol. 76, 10894-10904.

(58) Edwards, C., and Marks, R. (1995) Evaluation of biomechanical properties of human skin, Clinics in dermatology 13, 375-380.

(59) Satoh, T., and Arase, H. (2008) HSV-1 infection through inhibitory receptor, PILRalpha, Uirusu 58, 27-36.

(60) Akhtar, J., and Shukla, D. (2009) Viral entry mechanisms: cellular and viral mediators of herpes simplex virus entry, FEBS J. 276, 7228-7236. DOI: 10.1111/j.17424658.2009.07402.x.

(61) Kimberlin, D. W. (2005) Herpes simplex virus infections in neonates and early childhood, In Seminars in Pediatric Infectious Diseases, pp 271-281, Elsevier.

(62) Bergelson, J. M. (2009) Intercellular junctional proteins as receptors and barriers to virus infection and spread, Cell Host Microbe 5, 517-521.

(63) Gianni, T., Campadelli-Fiume, G., and Menotti, L. (2004) Entry of herpes simplex virus mediated by chimeric forms of nectin1 retargeted to endosomes or to lipid rafts occurs through acidic endosomes, J. Virol. 78, 12268-12276. DOI: 10.1128/Jvi.78.22.12268-12276.2004.

(64) Tiwari, V., and Shukla, D. (2010) Phosphoinositide 3 kinase signalling may affect multiple steps during herpes simplex virus type-1 entry, J. Gen. Virol. 91, 3002-3009. DOI: 10.1099/vir.0.024166-0.

(65) Zheng, K., Xiang, Y., Wang, X., Wang, Q., Zhong, M., Wang, S., Wang, X., Fan, J., Kitazato, K., and Wang, Y. (2014) Epidermal Growth Factor Receptor-PI3K Signaling Controls Cofilin Activity To Facilitate Herpes Simplex Virus 1 Entry into Neuronal Cells, mBio 5, e00958-00913. DOI: 10.1128/mBio.00958-13 ARTN e00958-13.

(66) Frampton, A. R., Jr., Stolz, D. B., Uchida, H., Goins, W. F., Cohen, J. B., and Glorioso, J. C. (2007) Equine herpesvirus 1 enters cells by two different pathways, and infection requires the activation of the cellular kinase ROCK1, J. Virol. 81, 10879-10889. DOI: 10.1128/JVI.00504-07.

(67) Hall, A. (2009) The cytoskeleton and cancer, Cancer Metastasis Rev. 28, 5-14. DOI: 10.1007/s10555-008-9166-3. (68) McNeil, P. L. (2002) Repairing a torn cell surface: make way, lysosomes to the rescue, J. Cell Sci. 115, 873879.

(69) Stampfer, S. D., Lou, H., Cohen, G. H., Eisenberg, R. J., and Heldwein, E. E. (2010) Structural basis of local, pHdependent conformational changes in glycoprotein B from herpes simplex virus type 1, J. Virol. 84, 12924-12933. DOI: 10.1128/JVI.01750-10.

(70) Glauser, D. L., Kratz, A. S., Gillet, L., and Stevenson, P. G. (2011) A mechanistic basis for potent, glycoprotein Bdirected gammaherpesvirus neutralization, J. Gen. Virol. 92, 2020-2033. DOI: 10.1099/vir.0.032177-0.

(71) Glauser, D. L., Kratz, A. S., and Stevenson, P. G. (2012) Herpesvirus glycoproteins undergo multiple antigenic changes before membrane fusion, PLoS One 7, e30152. DOI: 10.1371/journal.pone.0030152.
(72) Takahashi, K., Nakanishi, H., Miyahara, M., Mandai, K., Satoh, K., Satoh, A., Nishioka, H., Aoki, J., Nomoto, A., Mizoguchi, A., and Takai, Y. (1999) Nectin/PRR: an immunoglobulin-like cell adhesion molecule recruited to cadherin-based adherens junctions through interaction with Afadin, a PDZ domain-containing protein, J. Cell Biol. 145, 539-549.

(73) Stiles, K. M., Whitbeck, J. C., Lou, H., Cohen, G. H., Eisenberg, R. J., and Krummenacher, C. (2010) Herpes simplex virus glycoprotein D interferes with binding of herpesvirus entry mediator to its ligands through downregulation and direct competition, J. Virol. 84, 1164611660. DOI: $10.1128 /$ JVI.01550-10.

(74) MacLean-Fletcher, S., and Pollard, T. D. (1980) Mechanism of action of cytochalasin B on actin, Cell 20, 329-341.

(75) Rosenthal, K. S., Perez, R., and Hodnichak, C. (1985) Inhibition of herpes simplex virus type 1 penetration by cytochalasins B and D, J. Gen. Virol. 66 ( Pt 7), 1601-1605.

(76) Schwarz, B. T., Wang, F., Shen, L., Clayburgh, D. R., Su, L., Wang, Y., Fu, Y. X., and Turner, J. R. (2007) LIGHT signals directly to intestinal epithelia to cause barrier dysfunction via cytoskeletal and endocytic mechanisms, Gastroenterology 132, 2383-2394. DOI: 10.1053/j.gastro.2007.02.052.

(77) Arii, J., Uema, M., Morimoto, T., Sagara, H., Akashi, H., Ono, E., Arase, H., and Kawaguchi, Y. (2009) Entry of herpes simplex virus 1 and other alphaherpesviruses via the paired immunoglobulin-like type 2 receptor $\alpha, J$. Virol. 83 , 4520-4527.

(78) Sakamoto, Y., Ogita, H., Hirota, T., Kawakatsu, T., Fukuyama, T., Yasumi, M., Kanzaki, N., Ozaki, M., and Takai, Y. (2006) Interaction of integrin alpha(v)beta3 with nectin. Implication in cross-talk between cell-matrix and cell-cell junctions, J. Biol. Chem. 281, 19631-19644. DOI: 10.1074/jbc.M600301200.

(79) Giancotti, F. G., and Ruoslahti, E. (1999) Integrin signaling, Science 285, 1028-1032.

(80) Nebl, T., Pestonjamasp, K. N., Leszyk, J. D., Crowley, J. L., Oh, S. W., and Luna, E. J. (2002) Proteomic analysis of a detergent-resistant membrane skeleton from neutrophil plasma membranes, J. Biol. Chem. 277, 43399-43409. DOI: 10.1074/jbc.M205386200.

(81) Li, D., Miller, M., and Chantler, P. D. (1994) Association of a cellular myosin II with anionic phospholipids and the neuronal plasma membrane, Proc. Natl. Acad. Sci. U. S. A. 91, 853-857.

(82) Arii, J., Goto, H., Suenaga, T., Oyama, M., KozukaHata, H., Imai, T., Minowa, A., Akashi, H., Arase, H., Kawaoka, Y., and Kawaguchi, Y. (2010) Non-muscle myosin IIA is a functional entry receptor for herpes simplex virus-1, Nature 467, 859-862. DOI: 10.1038/nature09420.

(83) Vicente-Manzanares, M., Ma, X., Adelstein, R. S., and Horwitz, A. R. (2009) Non-muscle myosin II takes centre stage in cell adhesion and migration, Nat. Rev. Mol. Cell Biol. 10, 778-790. DOI: 10.1038/nrm2786.

(84) Olden, K., Willingham, M., and Pastan, I. (1976) Cell surface myosin in cultured fibroblasts, Cell 8, 383-390.

(85) Nicola, A. V., McEvoy, A. M., and Straus, S. E. (2003) Roles for endocytosis and low $\mathrm{pH}$ in herpes simplex virus entry into HeLa and Chinese hamster ovary cells, J. Virol. 77, 5324-5332.

(86) Milne, R. S., Nicola, A. V., Whitbeck, J. C., Eisenberg, R. J., and Cohen, G. H. (2005) Glycoprotein D receptordependent, low-pH-independent endocytic entry of herpes 
simplex virus type 1, J. Virol. 79, 6655-6663. DOI: 10.1128/JVI.79.11.6655-6663.2005.

(87) Clement, C., Tiwari, V., Scanlan, P. M., Valyi-Nagy, T., Yue, B. Y., and Shukla, D. (2006) A novel role for phagocytosis-like uptake in herpes simplex virus entry, $J$. Cell Biol. 174, 1009-1021. DOI: 10.1083/jcb.200509155.

(88) Gillet, L., Colaco, S., and Stevenson, P. G. (2008) Glycoprotein B switches conformation during murid herpesvirus 4 entry, J. Gen. Virol. 89, 1352-1363. DOI: 10.1099/vir.0.83519-0.

(89) Dollery, S. J., Delboy, M. G., and Nicola, A. V. (2010) Low $\mathrm{pH}$-induced conformational change in herpes simplex virus glycoprotein B, J. Virol. 84, 3759-3766. DOI: 10.1128/JVI.02573-09.

(90) Wheeler, C. E., Jr. (1975) Pathogenesis of recurrent herpes simplex infections, J. Invest. Dermatol. 65, 341-346.

(91) Fuller, A. O., and Lee, W. C. (1992) Herpes simplex virus type 1 entry through a cascade of virus-cell interactions requires different roles of $\mathrm{gD}$ and $\mathrm{gH}$ in penetration, J. Virol. 66, 5002-5012.

(92) Akhtar, J., Tiwari, V., Oh, M. J., Kovacs, M., Jani, A., Kovacs, S. K., Valyi-Nagy, T., and Shukla, D. (2008) HVEM and nectin-1 are the major mediators of herpes simplex virus 1 (HSV-1) entry into human conjunctival epithelium, Invest. Ophthalmol. Visual Sci. 49, 4026-4035. DOI: $10.1167 /$ Iovs.08-1807.

(93) Gruenheid, S., Gatzke, L., Meadows, H., and Tufaro, F. (1993) Herpes simplex virus infection and propagation in a mouse $\mathrm{L}$ cell mutant lacking heparan sulfate proteoglycans, J. Virol. 67, 93-100.

(94) Pertel, P. E., Fridberg, A., Parish, M. L., and Spear, P. G. (2001) Cell fusion induced by herpes simplex virus glycoproteins $\mathrm{gB}, \mathrm{gD}$, and $\mathrm{gH}-\mathrm{gL}$ requires a $\mathrm{gD}$ receptor but not necessarily heparan sulfate, Virology 279, 313-324. DOI: $10.1006 /$ viro.2000.0713.

(95) Fuller, A. O., and Spear, P. G. (1987) Antiglycoprotein D antibodies that permit adsorption but block infection by herpes simplex virus 1 prevent virion-cell fusion at the cell surface, Proc. Natl. Acad. Sci. U. S. A. 84, 5454-5458.

(96) Wittels, M., and Spear, P. G. (1991) Penetration of cells by herpes simplex virus does not require a low $\mathrm{pH}$ dependent endocytic pathway, Virus Res. 18, 271-290.

(97) Morgan, C., Rose, H. M., and Mednis, B. (1968) Electron microscopy of herpes simplex virus. I. Entry, $J$. Virol. 2, 507-516.

(98) Bender, F. C., Whitbeck, J. C., Ponce de Leon, M., Lou, H., Eisenberg, R. J., and Cohen, G. H. (2003) Specific association of glycoprotein $\mathrm{B}$ with lipid rafts during herpes simplex virus entry, J. Virol. 77, 9542-9552.

(99) Rahn, E., Petermann, P., Hsu, M. J., Rixon, F. J., and Knebel-Morsdorf, D. (2011) Entry Pathways of Herpes Simplex Virus Type 1 into Human Keratinocytes Are Dynamin- and Cholesterol-Dependent, PLoS One 6. DOI: ARTN e25464 DOI 10.1371/journal.pone.0025464.

(100) Highlander, S. L., Sutherland, S. L., Gage, P. J., Johnson, D. C., Levine, M., and Glorioso, J. C. (1987) Neutralizing monoclonal antibodies specific for herpes simplex virus glycoprotein D inhibit virus penetration, $J$. Virol. 61, 3356-3364.

(101) Highlander, S. L., Cai, W. H., Person, S., Levine, M., and Glorioso, J. C. (1988) Monoclonal antibodies define a domain on herpes simplex virus glycoprotein B involved in virus penetration, J. Virol. 62, 1881-1888.

(102) Fuller, A. O., Santos, R. E., and Spear, P. G. (1989) Neutralizing antibodies specific for glycoprotein $\mathrm{H}$ of herpes simplex virus permit viral attachment to cells but prevent penetration, J. Virol. 63, 3435-3443.

(103) Rand, R., and Parsegian, V. (1984) Physical force considerations in model and biological membranes, Canadian journal of biochemistry and cell biology 62, 752759.

(104) Zimmerberg, J., and Chernomordik, L. V. (1999) Membrane fusion, Advanced drug delivery reviews 38, $197-$ 205.

(105) Johnson, D. C., Burke, R. L., and Gregory, T. (1990) Soluble forms of herpes simplex virus glycoprotein D bind to a limited number of cell surface receptors and inhibit virus entry into cells, J. Virol. 64, 2569-2576.

(106) Nicola, A. V., Peng, C., Lou, H., Cohen, G. H., and Eisenberg, R. J. (1997) Antigenic structure of soluble herpes simplex virus (HSV) glycoprotein D correlates with inhibition of HSV infection, J. Virol. 71, 2940-2946.

(107) Cocchi, F., Fusco, D., Menotti, L., Gianni, T., Eisenberg, R. J., Cohen, G. H., and Campadelli-Fiume, G. (2004) The soluble ectodomain of herpes simplex virus gD contains a membrane-proximal pro-fusion domain and suffices to mediate virus entry, Proc. Natl. Acad. Sci. U. S. A. 101, 7445-7450. DOI: 10.1073/pnas.0401883101.

(108) Tsvitov, M., Frampton, A. R., Jr., Shah, W. A., Wendell, S. K., Ozuer, A., Kapacee, Z., Goins, W. F., Cohen, J. B., and Glorioso, J. C. (2007) Characterization of soluble glycoprotein D-mediated herpes simplex virus type 1 infection, Virology 360, 477-491. DOI: 10.1016/j.virol.2006.10.039.

(109) Jähnig, F. (1996) What is the surface tension of a lipid bilayer membrane?, Biophys. J. 71, 1348-1349.

(110) Silverman, J. L., Sharma, S., Cairns, T. M., and Heldwein, E. E. (2010) Fusion-deficient insertion mutants of herpes simplex virus type 1 glycoprotein B adopt the trimeric postfusion conformation, J. Virol. 84, 2001-2012. DOI: 10.1128/JVI.01791-09.

(111) Atanasiu, D., Cairns, T. M., Whitbeck, J. C., Saw, W. T., Rao, S., Eisenberg, R. J., and Cohen, G. H. (2013) Regulation of herpes simplex virus gB-induced cell-cell fusion by mutant forms of $\mathrm{gH} / \mathrm{gL}$ in the absence of $\mathrm{gD}$ and cellular receptors, mBio 4, e00046-00013. DOI: 10.1128/mBio.00046-13.

(112) Rey, F. A. (2006) Molecular gymnastics at the herpesvirus surface, EMBO Rep. 7, 1000-1005. DOI: 10.1038/sj.embor.7400807.

(113) Chi, J. H. I., Harley, C. A., Mukhopadhyay, A., and Wilson, D. W. (2005) The cytoplasmic tail of herpes simplex virus envelope glycoprotein $\mathrm{D}$ binds to the tegument protein VP22 and to capsids, J. Gen. Virol. 86, 253-261. DOI: 10.1099/vir.0.80444-0.

(114) Togo, T., and Steinhardt, R. A. (2004) Nonmuscle myosin IIA and IIB have distinct functions in the exocytosis-dependent process of cell membrane repair, Mol. Biol. Cell 15, 688-695.

(115) Laine, R. F., Albecka, A., van de Linde, S., Rees, E. J., Crump, C. M., and Kaminski, C. F. (2015) Structural analysis of herpes simplex virus by optical super-resolution imaging, Nat. Commun. 6, 5980. DOI: 10.1038/ncomms6980.

(116) Minson, A., Hodgman, T., Digard, P., Hancock, D., Bell, S., and Buckmaster, E. (1986) An analysis of the biological properties of monoclonal antibodies against glycoprotein D of herpes simplex virus and identification of amino acid substitutions that confer resistance to neutralization, J. Gen. Virol. 67, 1001-1013. DOI: 10.1099/0022-1317-67-6-1001. 
(117) Grünewald, K., Desai, P., Winkler, D. C., Heymann, J. B., Belnap, D. M., Baumeister, W., and Steven, A. C. (2003) Three-dimensional structure of herpes simplex virus from cryo-electron tomography, Science 302, 1396-1398. DOI: $10.1126 /$ science. 1090284 .

(118) Clarke, R. W., Monnier, N., Li, H., Zhou, D., Browne, H., and Klenerman, D. (2007) Two-color fluorescence analysis of individual virions determines the distribution of the copy number of proteins in herpes simplex virus particles, Biophys. J. 93, 1329-1337. DOI: 10.1529/biophysj.107.106351.

(119) Pettersen, E. F., Goddard, T. D., Huang, C. C., Couch, G. S., Greenblatt, D. M., Meng, E. C., and Ferrin, T. E. (2004) UCSF Chimera-A visualization system for exploratory research and analysis, J. Comput. Chem. 25, 1605-1612. DOI: 10.1002/jcc.20084.

(120) Berman, H. M., Westbrook, J., Feng, Z., Gilliland, G., Bhat, T., Weissig, H., Shindyalov, I. N., and Bourne, P. E. (2000) The protein data bank, Nucleic Acids Res. 28, 235242 .

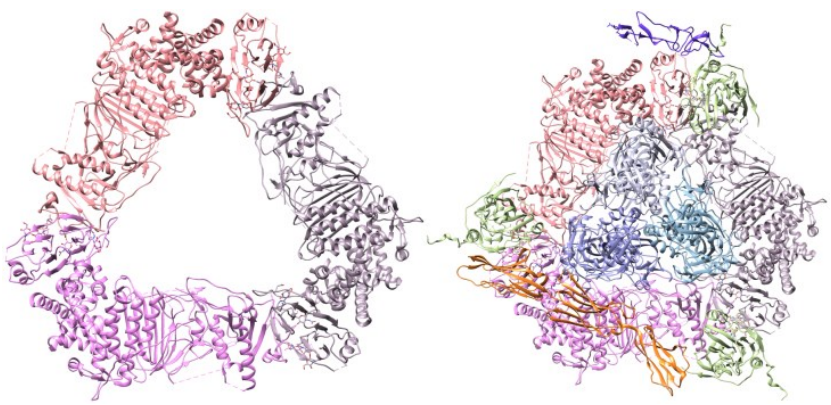

Synopsis: Three gHgL heterodimers, each held down by gD, sterically stabilize a compact form of the fusogen $\mathrm{gB}$. Once all three $\mathrm{gD}$ glycoproteins bind cellular receptors, holding the plasma membrane taut and directly adjacent, the displacement of the $\mathrm{gD}$ linker regions allows the $\mathrm{gHgL}$ triangle to open. The hairpin loops of $\mathrm{gB}$ are then free to rotate anti-clockwise, whereupon the central fusogen springs up into the plasma membrane, bolstered by virally-induced internalization of the $\mathrm{gD}$ receptors, to produce membrane fusion. On some cell types other virally induced forces can endocytose the virion before the full activation of the superstructure. 
Additional figures showing the gHgL triangle (S1) and the approximate scale of the disordered gD linker (S2):
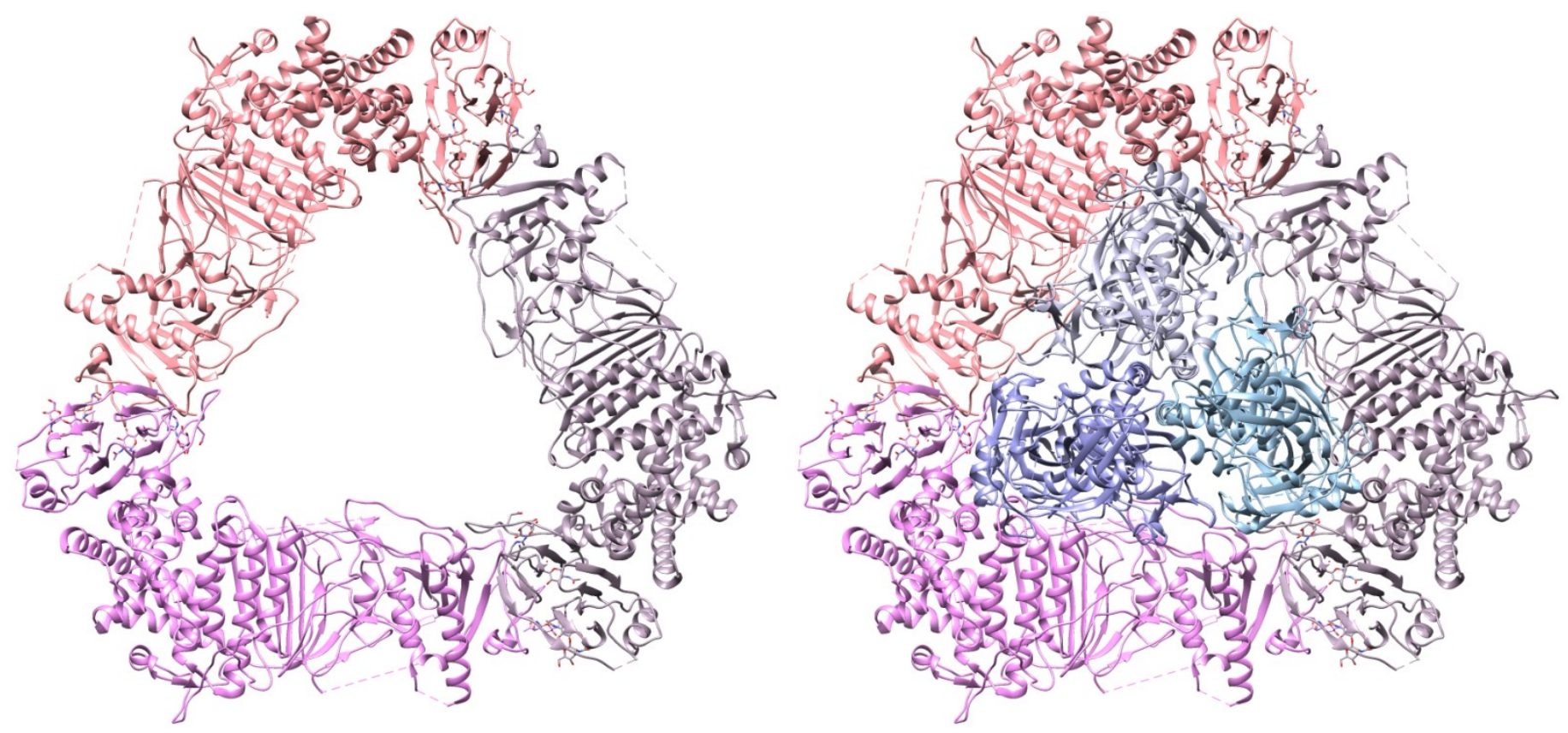

Figure S1. Triangle of three tessellated $\mathrm{gHgL}$ heterodimers. Left: Without $\mathrm{gB}$. Right: Surrounding the compact form of the gB trimer.

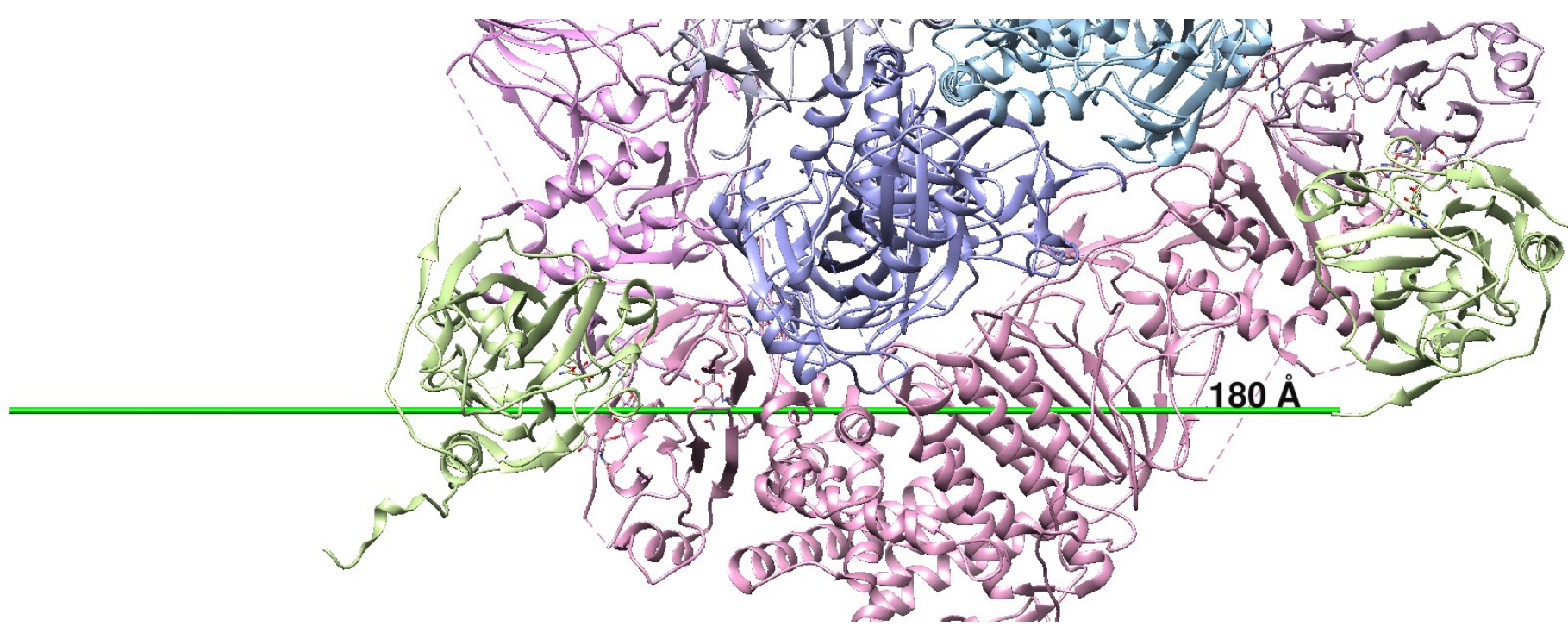

Figure S2. Scale of gD linker. A lower estimate for the scale of the gD linker, given that it is disordered. It easily reaches the putative binding regions on the lefthand $\mathrm{gHgL}$ with enough slack to double back to the transmembrane region of $\mathrm{gD}$. 